\title{
Government InTERVENTION In THE Housing Market: Who Wins, Who Loses?
}

\author{
Max Floetotto \\ Johannes Stroebel* \\ Stanford University \\ Stanford University
}

This version: February 25, 2010

\begin{abstract}
We study the effects of government intervention in the housing market on prices, quantities and welfare in a general equilibrium model with heterogeneous agents. We consider (i) the tax-deductibility of mortgage interest payments, and (ii) the exclusion of owner-occupied rents from taxation. We go beyond the existing literature and study both steady state effects as well as effects along the transition between steady states. When comparing stationary equilibria, we find that reducing asymmetries in the treatment of owner-occupied and rental housing in the tax code leads to welfare gains for all agents, as does the elimination of the mortgage interest deductibility. However, during the transition to the new steady-states, the welfare impacts are more varied. All agents benefit from the removal of the deduction of mortgage interest rates, due to general-equilibrium effects on prices and an increase in lump-sum transfers through higher government revenues. However, the introduction of taxes on imputed rents leads to significant welfare losses for all households that consume owner-occupied housing. This highlights the importance of focusing on the transition period for policy analysis.
\end{abstract}

Keywords: Housing Market, Policy Evaluation

JEL codes: C6, E21, E6, H21, R21

\footnotetext{
* Monika Piazzesi and Martin Schneider provided insightful discussions and encouragement. We would like to thank seminar audiences in the Stanford Macro Lunch and the Finance Reading Group, as well as Douglas Bernheim, Nick Bloom, Robert Hall, Nir Jaimovich and Tim Landvoigt for helpful comments. Corresponding author: Johannes Stroebel, Stanford University, Department of Economics, 579 Serra Mall, Stanford, CA 94305, stroebel@stanford.edu.
} 


\section{Introduction}

Increasing home-ownership has been a US policy goal for decades, and a number of policies, tax rules and regulatory efforts have been directed at increasing the affordability and attractiveness of owner-occupied housing. Interventions in the housing market come in many forms. Mortgage interest rates are subsidized through the Government Sponsored Entities (GSEs) Fannie Mae, Freddie Mac and Ginnie Mae. The tax code favors owner-occupied over rental housing by exempting imputed rents on owner-occupied housing from income taxation. Moreover, property owners can deduct mortgage interest payments from their taxable income. This is true both for owner-occupiers and for landlords who can deduct mortgage interest payments as a business expense. In addition, the US government has recently employed a number of short-term incentives to boost house prices and encourage home-ownership. The Obama Administration's First Time Home Buyer Tax Credit is one example of such short-term interventions.

In addition to the policy-goal of increasing home-ownership, the housing market is important from a macroeconomic perspective. At the aggregate level, the value of the total housing stock amounts to 1.9 times GDP in the United States. ${ }^{1}$ At the micro level, owneroccupied housing is by far the largest asset in the portfolio of many households, with the house value often representing a multiple of personal net worth. ${ }^{2}$ This suggests that the welfare impacts of government interventions in the housing market are potentially large.

In this paper, we study the effects of policy intervention in the housing market on prices, quantities and welfare in a general equilibrium model with heterogeneous agents. We consider households who differ along a number of characteristics such as age, income, home value and financial wealth to ask who wins and who loses from a potential change of government policy. We focus on analyzing two specific government interventions in the housing market: (i) the tax-deductibility of mortgage interest payments, and (ii) the exclusion of rents derived from owner-occupied housing from taxation.

In the first part of the paper, we study static effects by comparing stationary equilibria under alternative policy regimes. This allows us to determine which type of agent would benefit from living in a country with a particular policy regime. More importantly, however, we extend our analysis to include the transition between relevant stationary equilibria. That is, we consider the path between the current policy environment and the proposed alternative regimes. This allows us to determine the winners and the losers should the US choose to change the current policy regime. Since the transition to a new steady state often takes a number of decades, analyzing the transition path is very important before any

\footnotetext{
${ }^{1}$ The value of the housing stock is taken from Flow of Funds data for 2005.

${ }^{2}$ Caplin et al. (1999) use the 1995 Survey of Consumer Finances to argue that the house makes up for $50-70 \%$ of the average homeowner's portfolio.
} 
policy recommendations can be made. Considering winners and losers along the transition is particularly important in a political process where current generations will decide on any policy changes.

When comparing stationary equilibria, we find that reducing asymmetries in the treatment of owner-occupied and rental housing in the tax code leads to welfare gains for all agents, as does the elimination of the mortgage interest deductibility. However, during the transition to the new steady-state, the welfare impacts are more varied. All agents benefit from the removal of the deduction of mortgage interest rates, due to general-equilibrium effects on prices and an increase in lump-sum transfers through higher government revenues. However, the introduction of taxes on imputed rents leads to significant welfare losses for all households that consume owner-occupied housing.

In our model, forward-looking agents choose between owning or renting as a means to obtain housing services. Our setup differs from most of the existing literature in the way we model the rental market. The supply of rental units will come from other homeowners in the model who decide to become landlords and provide housing services to the market. In this framework, the house and rental prices are endogenous and the ratio of the two will not necessarily be constant. A similar setup appears in Chambers, Garriga and Schlagenhauf (2006). Other papers that model the housing market usually take a different, analytically more convenient approach with respect to the rental market. In those papers, there is a rental agency or investment firm that buys housing stock and rents it to households. This investment firm solves a static problem and a zero-profit condition forces rental prices to adhere to a simple no arbitrage condition that ties the rental price to the interest rate, depreciation rate of the housing stock and a maintenance cost parameter. Variants of this formulation can be found in Gervais (2002) and Yang (2005). This approach has two disadvantages. First, the price-rent ratio in those models is generally fixed which is at odds with the empirical evidence. We show that in our more flexible formulation, changes in government policy have a significant effect on the price-rent ratio, and thus the housing tenure decision. Second, the "buy-to-let" strategy that we consider in our model seems to be the rule rather than the exception as rental units are predominantly supplied by private investors. ${ }^{3}$ Changes in the level of rents will thus directly affect the budget constraints not only of renters, but also of those households that choose to become landlords.

We believe that any serious welfare analysis of policy alternatives needs to be conducted in a general equilibrium setting as equilibrium aspects are key for understanding the welfare

\footnotetext{
${ }^{3}$ Chambers, Garriga and Schlagenhauf (2006) cite evidence from the Census Bureau's 1996 Property Owners and Managers Survey (POMS). The sample includes 16,300 units of which 79 percent are residential. The authors report that $86.3 \%$ of all rental units are owned by individual investors. This number increases to $94 \%$ for non-institutional owners which are defined as individual investors, trustees of an estate, limited and general partnerships.
} 
consequences of policy alternatives. The reason is that the distributional effects are often less obvious than they might appear at first. Consider, for example, the policy to allow home owners to deduct mortgage interest payments from their taxable income. At first glance, this policy appears to be favoring those high-income households that are most likely to be homeowners. Since lost tax revenue will need to be raised in other ways, it is often claimed that mortgage interest deductions subsidize the rich. ${ }^{4}$ In a general equilibrium framework, however, the effects are not so clear. To the extent that the mortgage interest deductions encourage marginal buyers to leave the rental market and purchase a house, the resulting decline in demand for rental units may lower rents paid by low-income households. Furthermore, when mortgage interest deductions encourage more households to engage in "buy-to-let" investments, the supply of rental housing might increase. Both channels make rental housing more affordable and benefit low-income households. The overall welfare and distributional effects are thus unclear a priori. This example illustrates the benefits of applying a general equilibrium model of the housing market to analyze policy. ${ }^{5}$

Related Literature: There are a number of recent papers that study the implications of government intervention in the housing market. ${ }^{6}$ While the research questions are often similar to ours, these studies do not generally consider the transition between steady states which we find to be critical for our results. At most, the authors provide an intuitive discussion of how their long run results would be reinforced or weakened during the transition. This limits the usefulness of those analyses from a policy perspective.

The paper by Chambers, Garriga and Schlagenhauf (2006) is probably closest to our approach, particularly in the formulation of the rental market. They study the effect of the asymmetric tax treatment of homeowners and landlords in a quantitative general equilibrium overlapping generations model with housing and rental markets. Welfare consequences of removing the asymmetry in the existing tax code depend critically on whether the reform is revenue neutral. A revenue neutral reform implies modest welfare gains while a reform that's not revenue neutral leads to significant welfare losses. The authors do not consider

\footnotetext{
${ }^{4}$ For example, Poterba and Sinai (2008) analyze the current distribution of tax benefits associated with mortgage interest and property tax deduction. They report that the average home-owner saves $\$ 1,060$ as a result of mortgage interest deduction, but argues that the benefits of this is much bigger for high-income households. For 25-35 year old homeowners with over $\$ 250,000$ in income, the mortgage interest tax saving is $\$ 7,077$. These tax savings decline with age, as households gradually reduce to loan-to-value ratio of their mortgages.

${ }^{5}$ Poterba and Sinai (2008) acknowledge this in their empirical analysis of the the beneficiaries of the current tax treatment of owner-occupied housing and mortgage interest payments. They comment that 'changes in user cost $[. .$.$] translate into changes in housing demand and would affect real house prices and the quantity$ of housing in a manner that depends on housing market conditions'.

${ }^{6}$ More generally, there is a wide range of papers that focus on housing in a macroeconomic framework. These include Davis and Heathcote (2005), Kahn (2007), Piazzesi, Schneider and Tuzel (2007), FernandezVillaverde and Krueger (2007), Iaccoviello (2005), Iaccoviello and Neri (2009), Lustig and van Nieuwerburgh (2005), Nakajima (2005), Ortalo-Magne and Rady (2006), Landvoigt (2010), Yang (2005) and Silos (2007).
} 
the transition between possible steady states.

Gervais (2002) examines preferential tax treatment of housing capital in a dynamic life-cycle economy where housing rental services are provided by a rental firm. In his model, the tax system introduces a wedge that makes owing preferable to renting. He finds that mortgage interest deductions and the taxation of imputed rents have only very small distributional effects.

Jeske and Krueger (2007) build a general equilibrium model with competitive housing and mortgage markets where the government provides banks with insurance against aggregate shocks through its implicit guarantees for GSEs. The guarantee implies a mortgage interest subsidy to homeowners which leads to a higher housing stock and increased default rates as mortgage holders increase their leverage. The subsidy benefits mostly high income and high wealth households, and its elimination would lead to an aggregate welfare gain.

The only paper in this literature that we are aware of which contains an explicit transition path between stationary equilibria is by Kiyotaki, Michaelides and Nikolov (2009). The authors study the redistributional consequences of aggregate shocks through their effect on house prices. They construct a general equilibrium life-cycle model of a production economy where capital and land are used to build residential and commercial real estate. When the share of land in real estate is large, an exogenous shock to expected productivity or the world interest rate leads to large swings in house prices and a significant redistribution between net buyers and net sellers of houses. Their model does not incorporate the tax treatment of real estate, and does thus not allow to analyze the impact of the government interventions we consider.

The remainder of this paper is organized as follows. Section 2 introduces the model. We describe the government interventions in detail in section 3, and show how they are included in our model. In section 4 we discuss the calibration of our baseline economy. The comparison of stationary equilibria under different policy regimes appears in section 5 . Section 6 covers the transition path between those equilibria. Section 7 concludes.

\section{Model}

To analyze the distributional effects of government interventions in the housing market, we build an overlapping-generations equilibrium model of the housing and rental market. Households derive utility from both housing services and a nondurable consumption good. To obtain housing services, households decide whether to live in owner-occupied housing or rental housing. In addition, homeowners can decide to follow a "buy-to-let" strategy. This involves purchasing additional housing stock and renting those units out to other households. The model allows for a flexible set of non-convex transaction costs for house 
Figure 1: Stylized Model of the Housing Market

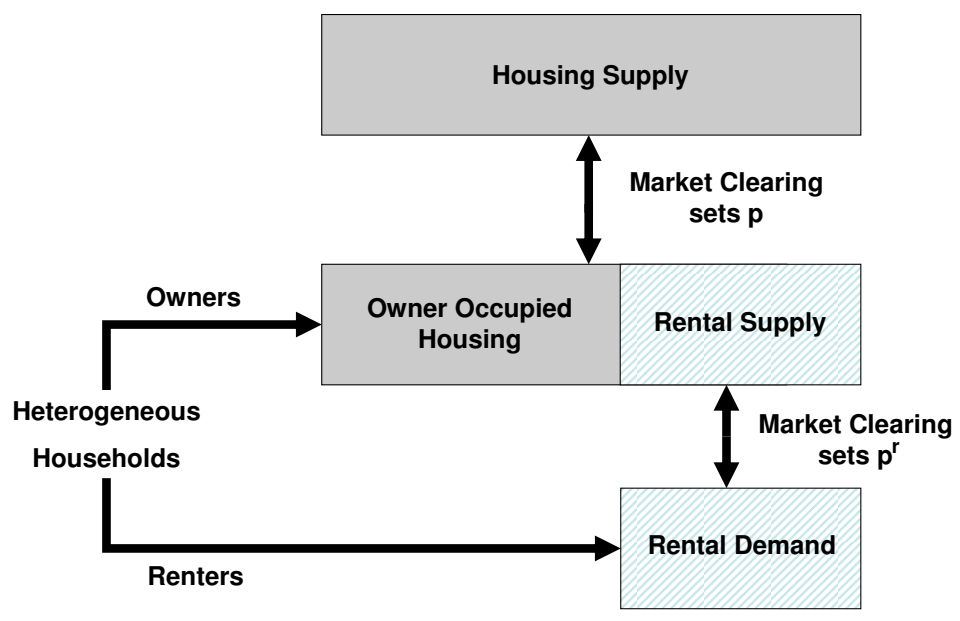

purchases. The government intervenes in a number of ways and thus affects household decisions. For a given supply of housing units, the aggregate demand for owner-occupied and rental housing is derived from the aggregation of individual household decisions. The solution to the household problem also yields the supply of and demand for rental units. House prices $p$ and rents $p^{r}$ adjust to clear both the housing and the rental market. Figure 1 illustrates this setup.

\subsection{Housing Services and Transaction Costs}

To receive housing services, agents can either purchase or rent housing units. Home owners have the additional option to supply some of those units to the rental market. In terms of our notation, household can rent, $h^{r}>0$, or own, $h>0$. Owners can also choose to become landlords, a let some units $h^{r}<0$ to other households. The amount of housing services $\tilde{h}$ that an agent consumes is then given by

$$
\tilde{h}= \begin{cases}h^{r} & \text { if Renter }\left(h^{r}>0\right) \\ h+h^{r} & \text { if Owner }\left(h^{r} \leq 0\right) .\end{cases}
$$

This set-up allows us to distinguish the consumption aspect of housing from the investment aspect of housing. The maximum amount of housing leased to other households is limited by an agent's owned housing stock. This formulation assumes that a household can only live in one place at a time, and will therefore either derive utility from the amount of 
rented housing or from the amount of owned housing that is not leased to other people. Households cannot augment their housing consumption by renting additional units on top of their owner-occupied home. ${ }^{7}$

We assume that an agent's housing stock depreciates at rate $\delta$ each period. We also assume that buying and selling houses as well as the process of moving generate substantial costs. These include for example the time cost of searching for a suitable home, broker fees, taxes and necessary remodeling work in the new house. In our model, an agent who buys a house incurs a cost as a fraction $\phi^{\text {buy }}$ of the value of the new house, $p h$. Similarly, an agent who sells her home incurs a cost as a fraction $\phi^{\text {sell }}$ of the value of the house she is selling, $p h_{-1}(1-\delta)$. Our formulation of transaction costs is specified below.

$$
A C\left(h_{-1}, h\right)= \begin{cases}0 & \text { if } h=(1-\delta) h_{-1} \\ p\left(\phi^{\text {buy }} h+\phi^{\text {sell }} h_{-1}(1-\delta)\right) & \text { otherwise }\end{cases}
$$

The cost of moving between rental units is arguably smaller. Most households that rent a new apartment do not engage in expensive remodeling work and brokerage fees are - if applicable at all - much lower. In our simulations, we normalize moving costs for renters to zero. This allows a substantial numerical simplification as will become clear in appendix A.1.

The decision to become a landlord, on the other hand, involves non-trivial costs. The owners of rental units need to search for and screen potential renters, conduct substantial administrative work and carry the risk of not being paid the rent because of unfilled inventory (though this is not explicitly modeled here). For convenience, we model this cost as a fixed per period cost $\xi$.

\subsection{Setup of the Household Problem}

Agents receive utility from consuming housing services $\tilde{h}$ and the nondurable consumption good $c$ which is used as a numeraire. Preferences over consumption and housing services are non-separable. Everything else equal, agents prefer owner-occupied housing to rental housing. Living in their own house allows them more freedom to tailor the house to their specific needs. ${ }^{8}$ Alternatively, one can think of this preference for owner-occupied housing as a reflection of a higher quality of the housing stock. In terms of the model, agents weigh

\footnotetext{
${ }^{7}$ One assumption here is that housing is divisible. Alternative modelling assumptions would require us to have a number of different types of housing (small, medium, big), with state variables for each, and market clearing for each in the rental and the purchase market. While this would potentially generate some more interesting predictions for different segments of the housing market, it would complicate the computational approach significantly, without adding additional insights for the questions we consider.

${ }^{8}$ There is significant evidence for this in the empirical literature. See, for example, Galster (1987) and Green and Malpezzi (2000).
} 
housing service with a factor $\lambda$ in their utility function, which takes a value of one for owner occupied housing and a value less than one for rental housing.

$$
u(c, \tilde{h})={\frac{\left(c^{\alpha}+\omega(\lambda \tilde{h})^{\alpha}\right)^{\frac{1-\rho}{\alpha}}}{1-\rho}}^{\frac{1-\rho}{2}}
$$

The agents' period utility function is standard in this literature. Note that $\alpha$ parameterizes the degree of complimentarity between housing and consumption while $\rho$ is the coefficient of relative risk aversion. ${ }^{9}$

Agents work for $J-1$ periods before they retire. In our simulations, we set the period length to be five years and $J$ to 10 , which leaves us with 9 working cohorts aged between 20-25 and 60-65. Once retired, agents face a constant mortality rate $\kappa$. An agent who dies unexpectedly sells the house on the market, services potential outstanding debt and consumes the proceeds. ${ }^{10}$ In every period, a new cohort of young agents enters the economy and replaces the dying retirees such that the overall mass of agents remains constant. In this setup, it is straightforward to calculate the stationary distribution of agents $\mu(i, j)$ over age groups $j$ and the productivity variable that we index with $i{ }^{11}$

Working agents are endowed with one unit of labor, which they supply inelastically, and have an age-specific productivity $\gamma_{j}$. They also face persistent idiosyncratic shocks to their labor productivity $\eta_{i, t}$. Given the wage rate $w_{t}$, labor income $y_{i, j, t}$ can be expressed as

$$
y_{i, j, t}=w_{t} \gamma_{j} \eta_{i, t}
$$

where $\eta_{i, t}$ is assumed to follow an $\operatorname{AR}(1)$ process in $\log$ terms with $|\phi|<1$ and $\varepsilon_{i, t} \sim N\left(0, \sigma_{\varepsilon}^{2}\right)$

$$
\log \eta_{i, t}=\phi \log \eta_{i, t-1}+\varepsilon_{i, t}
$$

Retirees receive Social Security benefits as a given fraction $g$ of the working population's

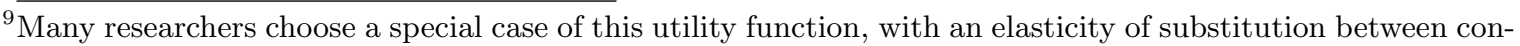
sumption and housing services of one. Examples are Krueger and Jeske (2007) as well as Chambers, Garriga and Schlagenhauf (2006). This parameterization simplifies the computational solution, but is inconsistent with most empirical estimates of this crucial parameter, as we discuss in section 4.1.

${ }^{10}$ This formulation of the life-cycle allows to abstract from inter-generational linkages through the bequest motive. Alternatively, one could specify an exogenous age $T$ at which agents exit the model and leave their remaining financial and housing wealth to their descendants. While there are of course bequests in reality, this seems to be a reasonable simplification given that most rental units were acquired by the current owner. Only $6.6 \%$ of all rental units are inherited or gifted and more than $75 \%$ of rental units were acquired in a mortgage financed transaction. See Chambers, Garriga and Schlagenhauf (2006) for details.

${ }^{11}$ There are $J-1$ working age cohorts of equal density $f$. The group of retirees consists of survivors of all non-working cohorts and has a total density $f /(1-\kappa)$. Therefore, the density of each working cohort is $f=(J+\kappa /(1-\kappa))^{-1}$.
} 
average income. Benefits are thus set at

$$
\bar{y}=g \sum_{j=1}^{J-1} \int_{i} y_{i, j} \mu(i, j) d i
$$

This social security payment is financed by a $\operatorname{tax} \tau^{s s}$ on labor income. We assume that the Social Security agency breaks even in every period and adjust the tax rate accordingly. ${ }^{12}$

Households have access to a risk free bond $s$ that pays interest $r .{ }^{13}$ Markets are incomplete in the sense that agents can only borrow against the value of their house. Their ability to hold debt is restricted by a downpayment requirement, $d$. That is, agents cannot hold debt in excess of their maximum mortgage.

$$
s^{\prime}>(1-d) h p
$$

When borrowing, agents pay a higher interest rate $r+m$ where the mortgage premium $m$ captures the probability of mortgage default in a reduced form. ${ }^{14}$

For an arbitrary policy regime, the sequential budget constraint of a working agent can be expressed as

$$
\begin{aligned}
& c+s^{\prime}+p h+A C= \\
& p^{r}(h-\tilde{h})+\left(1+r+m I_{\{s<0\}}\right) s+\left(1-\tau^{s s}\right) y+p(1-\delta) h_{-1}-\max \{0, T-D\}+T r
\end{aligned}
$$

where $T$ denotes the tax burden that comprises taxes on labor income, capital income and rental income. The sum of applicable tax deductions is denoted by $D$ and is capped at the level of the total tax owed. $\mathrm{Tr}$ represents a lump-sum transfer from the government to all agents - this transfer adjusts to ensure that the government breaks even every period. The government intervenes through the exact specification of $T$ and $D$. The policy alternatives considered in this paper will be presented in detail in section 3.2.

It is now possible to lay out the problem of the retiree and working agent in their recursive form. In the first part of the paper, we are concerned with stationary equilibria. For those, prices are constant and will be dropped from the set of state variables to simplify notation.

Problem of the Retiree: With constant prices, the problem of the retiree can be expressed

\footnotetext{
${ }^{12}$ As there is no aggregate uncertainty in the model, the tax-rate can be determined by the following equation: $\tau^{s s}\left[1-\frac{f}{1-\kappa}\right]=g \frac{f}{1-\kappa}$ so that $\tau^{s s}=g \frac{f}{1-\kappa-f}$.

${ }^{13}$ In the computational implementation, we follow Yao and Zhang (2005) who define voluntary savings instead of actual savings. See appendix A.3 for details.

${ }^{14}$ Note that there is no explicit mortgage default in our model. In a related paper, Krueger and Jeske (2007) include stochastic housing depreciation rates which implies that an unexpectedly high depreciation shock can lead homeowners to default on their mortgage.
} 
in recursive form as

$$
V^{J}\left(h_{-1}, s\right)=\max _{s \prime, h, \tilde{h}}\left\{u(c, \tilde{h})+(1-\kappa) \beta \mathbb{E} V^{J}\left(h, s^{\prime}\right)+\kappa(u(c+\varphi, \tilde{h})-u(c, \tilde{h}))\right\}
$$

subject to:

$$
\begin{aligned}
& c+s^{\prime}+p h+A C+T r= \\
& \quad p^{r}(h-\tilde{h})+\left(1+r+m I_{\{s<0\}}\right) s+\bar{y}+p(1-\delta) h_{-1}-\max \{0, T-D\}+T r \\
& \varphi=s^{\prime}\left(1+r+m I_{\{s<0\}}\right)+\left(1-\phi^{\text {sell }}\right)(1-\delta) p h^{\prime}
\end{aligned}
$$

$(1),(2),(3),(6),(7)$

Problem of the Working Cohorts: For the remaining cohorts 1 to $J-1$, the problem can be solved backwards. Again keeping prices constant, the problem of cohort $j$ can be expressed as

$$
V^{j}\left(h_{-1}, s, y\right)=\max _{s \prime, h, \tilde{h}}\left\{u(c, \tilde{h})+\beta \mathbb{E} V^{j+1}\left(h, s^{\prime}, y^{\prime}\right)\right\}
$$

subject to:

$$
\begin{aligned}
& c+s^{\prime}+p h+A C+T r= \\
& \quad p^{r}(h-\tilde{h})+\left(1+r+m I_{\{s<0\}}\right) s+\left(1-\tau^{s s}\right) y+p(1-\delta) h_{-1}-\max \{0, T-D\}+T r \\
& (1),(2),(3),(4),(5),(7)
\end{aligned}
$$

For a given set of prices, this is a standard problem that can be solved using well-known techniques. ${ }^{15}$ We close the model by specifying the determinants of housing supply. The section ends with a definition of the stationary equilibrium in this economy.

\subsection{Housing Supply and Market Clearing}

There is a competitive construction sector that transforms land $L$ into new housing stock $H^{\text {new }}$. This sector purchases land at a constant price that we normalize to 1 and immediately sells the housing stock in the market at price $p$. Profits of the construction firm are thus given by $p H^{\text {new }}-L$. We assume that every period a fixed amount of land is made available for development. Every period, as more of the available land is developed, developing additional units becomes more expensive. In other words, every period the land is developed in decreasing order of quality. This is reflected in decreasing returns in the production of new housing stock.

$$
H^{\text {new }}=\psi_{1} L^{\psi_{2}}
$$

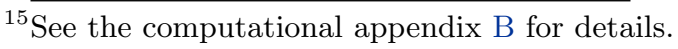


where $\psi_{2} \leq 1$. The construction firm thus solves the following static problem,

$$
\max _{L}\left\{p \psi_{1} L^{\psi_{2}}-L\right\}
$$

This can then be used to back out the optimal choice of new housing construction,

$$
H^{\text {new }}=\psi_{1}\left(\frac{1}{p \psi_{1} \psi_{2}}\right)^{\left(\frac{\psi_{2}}{\psi_{2}-1}\right)}
$$

This implies that at higher prices more resources are invested into housing construction; equivalently one can say that with higher prices progressively worse quality land is developed. The resulting law of motion for the aggregate housing stock is:

$$
H=H_{-1}(1-\delta)+H^{N e w}=H_{-1}(1-\delta)+\psi_{1}\left(\frac{1}{p \psi_{1} \psi_{2}}\right)^{\left(\frac{\psi_{2}}{\psi_{2}-1}\right)}
$$

Parameterizing the housing production function is relatively difficult, and housing supply elasticities vary hugely across cities and regions (this is discussed in more detail in section 4). In Appendix $\mathrm{C}$ we thus also run a robustness check of our results in a simulation where we keep the total stock of housing constant across steady states and along the transition path between steady states.

\subsection{Definition of a Stationary Equilibrium}

Purchase and rent prices for housing are determined every period by a market-clearing condition in both markets. As illustrated above, the supply of rental units is endogenous as rental units are supplied by households who decide to become landlords. The market clearing conditions are formally expressed as follows: ${ }^{16}$

$$
\begin{gathered}
\int_{i} h_{i} \mu(i)=H \\
\int_{i} h_{i}^{r} \mu(i)=0
\end{gathered}
$$

In our welfare comparisons, it will be important to consider the tax revenue implications of potential policy alternatives. In a steady-state equilibrium we require the government to

${ }^{16}$ This is clearly a simplification. It assumes that rents can adjust instantaneously, which is generally not the case. Transaction costs imply that rental contracts are adjusted infrequently and in special cases legal reasons like rent control prevent an immediate adjustment of prices. The model thus cannot integrate the importance of inventory build-up. 
run a balance budget in every period, that is:

$$
\int_{i} \max \{0, T(i)-D(i)\} d i=T r .
$$

For a given policy regime, we can now define a stationary equilibrium.

Given an institutional setup $T$ and $D$ that includes a set of government policies $\tau_{y}, \tau_{s}$ and $\tau_{r}$, a wage rate $w$, and an interest rate $r$, a stationary recursive competitive equilibrium is defined by prices $p$ and $p^{r}$, value and policy functions for households $V, c, h, h^{r}, s^{\prime}$, a policy for the construction sector $H^{\text {new }}$, a lump sum government transfer $\operatorname{Tr}$ and an invariable distribution of households $\mu$ (over $h, s, y, j$ ) such that

1. Given prices, households optimize,

2. Given prices, the construction sector optimizes,

3. The housing and rental markets clear,

4. The government budget breaks even in every period,

5. The distribution $\mu$ is invariant with respect to the exogenous Markov process for labor productivity and the policy functions $h$ and $s^{\prime}$.

\section{Government Intervention in the Housing Market}

There is a wide-spread belief that homeownership has important personal and societal benefits. On an individual level, homeownership seems to be associated with life satisfaction. ${ }^{17}$ Moreover, there are supposedly large positive externalities as homeowners have an incentive to take care of their property and their local neighborhood. ${ }^{18}$ Not surprisingly, government intervention is the housing market is large, and has been primarily directed at increasing homeownership rates. The National Homeownership Strategy (1995) states that "Homeownership is a commitment to strengthening families and good citizenship. Homeownership enables people to have greater control and exercise more responsibility over their living environment." In this section we describe the current US government interventions in the housing market, and discuss potential alternatives to the status quo. We show how the current institutional set-up and various alternatives would be integrated into our model economy.

\footnotetext{
${ }^{17}$ See, for example, Scanlon (1999). Rossi and Weber (1996) also report a positive relationship between homeownership and happiness in an analysis using the National Survey of Families and Households.

${ }^{18}$ Rohe and Stewart (1996) argue that homeownership improves social conditions like high school drop-out rates or crime rates.
} 


\subsection{Current Policy Regime and Potential Alternatives}

Among the most important aspects of the tax code that affect decision in the housing market are the income-tax exemption of imputed rents from owner-occupied housing and the deductibility of mortgage interest payments and property taxes from taxable income. ${ }^{19}$

In the US, a landlord pays taxes on the income received from rental units. At the same time, the implicit income from owner-occupied housing is exempt from income taxation. ${ }^{20}$ This asymmetry between landlords and owners leads to a bias in favor of owner-occupied housing. A repeal of this policy has been estimated to reduce overall housing consumption and increase business capital. ${ }^{21}$

Households that itemize can deduct mortgage interest payments from their tax bill. This is generally considered to be a subsidy that encourages homeownership and leads households to over-consume housing services. The effects of a repeal of this policies is controversial. Some expect homeownership rates to decrease by around 4 percentage points. ${ }^{22}$ Others find significantly smaller effects. ${ }^{23}$

\subsection{Government Intervention in the Model}

In our model, we consider an environment where the government taxes labor income, capital income and rental income. In our formulation, taxes are levied both on real rental income as well as imputed rental income for owner-occupied housing. In the benchmark calibration, however, taxes on imputed rents are deducted to make the model consistent with current US policy. Our policy experiments include a removal of the tax exemption of imputed rents from owner-occupied housing as well as an elimination of the mortgage interest rate deduction.

In terms of the model, a policy regime is determined by the specification of each agent's tax bill, $\max \{0, T-D\}$, which is itself a function of total tax owed $T$ and potential deductions $D$. The total tax burden can be broken down as follows.

$$
T=\sum\left(\begin{array}{l}
\tau^{y} y \\
\tau^{s} r s I_{\{s>0\}} \\
\tau^{r} p^{r} h
\end{array}\right) \begin{aligned}
& \text { labor income taxes } \\
& \text { capital income tax } \\
& \text { tax on rental income (real and imputed) }
\end{aligned}
$$

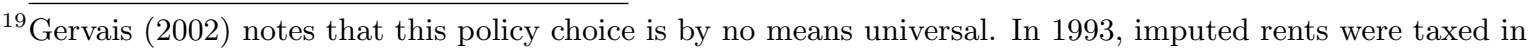
nine while mortgage interest was not tax deductible in five of 24 OECD countries.

${ }^{20}$ Property taxes and fees might be considered by some as an equivalent form of taxation. However, Fullerton (1984) has estimated these to be significantly lower than the income tax rate paid by landlords.

${ }^{21}$ Examples are Berkovec and Fullerton (1992) and Gervais (2002).

${ }^{22}$ Numbers in this range are found for example by Rosen (1979), Rosen and Rosen (1980) and Gervais (2002).

${ }^{23}$ See, for example, Berkovec and Fullerton (1992), Glaeser and Shapiro (2003) and Chambers, Garriga and Schlagenhauf (2006).
} 
Current deductions that are considered in this paper are summarized below, where the indicators $\Psi_{1}$ and $\Psi_{2}$ are used as a convenient way to combine policy alternatives in a single equation. ${ }^{24}$

$$
D=\sum\left(\begin{array}{l}
\Psi_{1} \cdot \tau^{r} \cdot \tilde{h} p^{r} I_{\{h>0\}} \\
\Psi_{2} \cdot \tau^{y} \cdot(-1)(r+m) s I_{\{s<0\}}
\end{array}\right) \begin{aligned}
& \text { no tax on owner-consumed housing services } \\
& \text { deductibility of all mortgage interest }
\end{aligned}
$$

In section 6.2 we discuss the government balance requirements along the transition path. A policy alternative that reduces tax revenues would also imply a reduction in the lump sum transfer agents receive from the government.

\section{Calibration}

In this section we describe the calibration of parameters used in the baseline model. Some parameters, such as preference and income process parameters are taken straight from the literature, where they have been previously estimated. Other parameters are calibrated using a method of moments approach. In particular, we calibrate the model so that the baseline steady state (with policy parameters $\Psi_{1}=1$ and $\Psi_{2}=1$ ) approximates relevant moments from the US economy. This procedure is described in more detail in the second part of this section.

\subsection{Calibration of Pre-Defined Parameter Values}

Table 1 summarizes the set of pre-defined parameters that we take as given and do not estimate in our model. We use parameters that are approximately in the center of the range of values used in the literature. Recall that a period in the model refers to a five year time span. However, to ease comparison with the existing literature we discuss the calibration in terms of annual values. For example, we choose an annual discount factor of 0.96 which corresponds to a discount factor $\beta$ of 0.815 in the model.

Preferences: The coefficient of relative risk aversion $\rho$ is set to 2 , which is a standard value in macroeconomics. ${ }^{25}$ The second important coefficient in the per period utility function (3) refers to the elasticity of substitution between nondurable consumption and housing services. Our choice for $\epsilon$ of 1.4 lies between the estimates of Schneider, Piazzesi and Tuzel

${ }^{24}$ More generally, the components of government policy can be turned on and off individually in the model. Appendix A.2 contains relevant details.

${ }^{25}$ The macro literature has for a long time followed Hall (1988) who proposed a value of 5 while many finance papers used even higher estimates. Using micro data, labor economists have recently estimated the intertemporal elasticity of substitution - the inverse of $\rho$ in our setup - to be much higher than 0.2. For instance, Attanasio and Browning (1995) report estimates for the intertemporal elasticity of substitution between 0.48 and 0.67. Pistaferri (2003) reports estimates for Italian man of around 0.7. Our choice of 2 for the coefficient of relative risk aversion can be regarded as a compromise. 
Table 1: Pre-Defined Parameter Values

\begin{tabular}{clcc}
\hline & & Model & Annual \\
& Parameter & Value & Value \\
\hline$\beta$ & Time discount factor & 0.815 & 0.960 \\
$\epsilon$ & Elasticity of substitution between $c$ and $\tilde{h}$ & 1.400 & - \\
$\rho$ & Coefficient of relative risk aversion & 2.000 & - \\
$1-\kappa$ & Conditional survival probability of retirees & 0.730 & 0.939 \\
$g$ & Replacement ratio & 0.386 & - \\
$\tau^{y}$ & Tax rate on labor income & 0.275 & - \\
$\tau^{r}$ & Tax rate on rental income & 0.275 & - \\
$\tau^{s}$ & Tax rate on capital income & 0.290 & - \\
$\phi^{\text {buy }}$ & Transaction costs for buyer (\% of house value) & 0.025 & - \\
$\phi^{\text {sell }}$ & Transaction costs for seller (\% of house value) & 0.060 & - \\
$\delta$ & Housing stock depreciation rate & 0.073 & 0.015 \\
$r$ & World interest rate & 0.292 & 0.053 \\
$m$ & Mortgage premium & 0.109 & 0.017 \\
$\phi$ & Persistence of income process & 0.850 & 0.968 \\
$\sigma_{\epsilon}^{2}$ & Variance of income innovations & 0.083 & 0.017 \\
$d$ & Downpayment requirement & 0.200 & - \\
$\psi_{1}$ & Production function parameter & 3.160 & - \\
$\psi_{2}$ & Production function parameter & 0.857 & - \\
\hline
\end{tabular}

Note: The third column lists the parameter value used in the model simulations. The fourth column shows the corresponding annual value if appropriate. Parameter choices and their sources are described in detail in the main text.

(2006) who report a value of 1.24 and the parameter value from McGrattan, Rogerson, and Wright (1997) who use 1.75. It also lies in the $95 \%$ interval found by Ogaki and Reinhart (1998). ${ }^{26}$

Demographics: We use the US Decennial Life Tables for 1989-1991 to calibrate mortality rates for retirees. In our model, we would optimally use age group specific mortality rates. However, given that we solve the problem of the retiree as an infinite horizon problem with constant mortality rate $\kappa$, we can only use a single parameter. We thus calibrate $1-\kappa$ as the conditional probability of a person aged 65 or above to survive the subsequent five years. This probability is around $73 \%$. Each period, the measure of newly born agents is equal to the measure of those who die and exit the model. As a result, the total population remains constant.

Taxes and Benefits: As discussed in section 2.2, after mandatory retirement at age 65, each agent receives a pension financed by a levy on labor income. Following Queisser and Whitehouse (2005) we set the replacement rate to 38.6 percent of economy-wide average earnings. This results in a tax rate of 15.8 percent which is very close to the 15.3 percent reported by Chen (2009) for the US. In calibrating average tax rates, we follow Diaz and

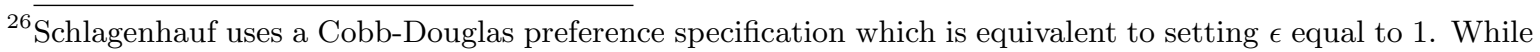
this is computationally attractive, Schneider, Piazzesi and Tuzel show that $\epsilon>1$. 
Luengo-Prado (2008). In one of their specifications, they use the US Federal and State Average Marginal Income Tax Rates in the NBER TAXSIM model to construct average tax rates on capital and labor income for the US. They find an average effective tax rate on capital income for the period 1996-2006 of 29.22\%. The average effective tax rate on labor for the same period is $27.54 \%$. We will use $29 \%$ and $27.5 \%$ in our simulations. Rental income in the US is included in the gross income on which the income tax rate is levied. In the base-line calculation we thus set the tax rate on rental income equal to the tax rate on labor income.

Adjustment Costs in the Housing Market: Smith, Rosen and Fallis (1988) estimate the transaction costs of changing owner-occupied housing to be approximately $8-10 \%$ of the value of the unit. This includes search and legal costs, costs of remodeling the unit and psychological costs from the disruption of social life. Yang (2005) assumes transaction costs from a sale to be $6 \%$ of the value of the unit sold, and transaction costs from a purchase to be $2 \%$ of the value of the unit bought. Iacoviello and Pavan (2009) assume adjustment costs of $4 \%$ of house value for both the purchasing and the selling party. Gruber and Martin (2003) estimate the tax and agency costs from relocation from the CEX. They find that the median household pays costs of the order of $7 \%$ of house value to sell their houses and $2.5 \%$ of value to purchase. To keep within these estimated literature values, in our baseline parameterization we assume costs of $6 \%$ of house value for sellers of the home, and costs of $2.5 \%$ for buyers of the home.

Depreciation of the Housing Stock: Leigh (1980) estimates the annual depreciation rate of housing units in the US to be between $0.36 \%$ and $1.36 \%$. Cocco (2005) uses a depreciation rate equal to $1 \%$ on an annual basis. Harding, Rosenthal and Sirmans (2007) use data from the American Housing Survey and a repeat sales model to estimate that between 1983 and 2001 housing depreciated at roughly 2.5\% per year gross of maintenance, while the net of maintenance depreciation rate was approximately $2 \%$ per year. Chen (2009) computes the depreciation rate for housing to match an average investment-capital ratio for private residential structures. This gives an annual depreciation rate of $2.05 \%$. Consistent with these estimates, in our baseline parameterization, we assume that the capital housing stock depreciates at an annual rate of $1.5 \%$.

Interest Rate and Mortgage Premium: We consider a small open economy model. The interest rate paid on the risk-free bond is fixed and taken as given at $1 / \beta$. When borrowing funds to buy a home, households pay a mortgage premium $m$ in addition to the interest rate $r$. Freddie Mac's Primary Mortgage Market Survey (PMMS) lists average annual interest rates for 30-year fixed rate mortgages. We calibrate the mortgage premium $m$ such that the mortgage rate $r+m$ is equal to an annual rate of $6.98 \%$, the average value for the period from 1995 to 2005. 
Income Process: Households supply one unit of labor inelastically. However, household productivity varies both across age groups and also stochastically across agents. Their wage income thus depends on two factors, the age-specific factor $\gamma_{j}$, and the stochastic, individual-specific factor $\eta_{i, t}$. The factor $\gamma_{j}$ is necessary to capture the hump-shape of individual earnings profiles over the life-cycle. The age-profile of labor efficiency units is taken from Hansen (1993) and approximated with a cubic spline. To parameterize $\eta_{i, t}$, we build on empirical work by Antonji and Villanueva (2003) whose estimates are also used by DeNardi (2004) and others. They use PSID data to estimate the idiosyncratic component of income as an $\mathrm{AR}(1)$ process. Aggregating the data to five year intervals, they report an autoregressive parameter $\phi$ of 0.85 and a variance of innovations $\sigma_{y}^{2}$ of 0.3 . This implies a value for $\sigma_{\epsilon}^{2}$ of 0.083 . We discretize this process to a 8-state Markov chain using the procedure of Tauchen and Hussey (1991) as described in Adda and Cooper (2003).

Downpayment Requirement: We set the downpayment requirement to $20 \%$ of the house value. This choice is consistent with much of the related literature, such as Chu (2009), Diaz and Luengo-Prado (2007) and Yang (2005). While in recent years some mortgages were available with lower downpayment requirements, those also required higher mortgage interest payments. In our model, all households face the same downpayment constraint and mortgage interest rate.

Housing Supply Elasticity: As discussed above, parameterizing the housing production function is very difficult. Empirical estimates of the price elasticity of housing supply vary widely. Blackley (1999) analyzes the real value of US private residential construction put in place. She finds elasticities ranging from 0.8 to 3.7 , depending on the dynamic specification of her model. Mayer and Somerville (2000) estimate a flow elasticity of 6 , suggesting that a $10 \%$ increase in house prices will lead to a $60 \%$ increase in housing starts. Furthermore, price elasticities of housing supply are likely to vary widely within the US. As argued by Glaeser, Gyourko, and Saks (2005) supply side regulation (and thus the price elasticity of housing starts) differs by region and city. Some authors, such as Chu (2009), Ortalo-Magne and Rady (2006) and Rios-Rull and Sanchez-Marcos (2007) have hence chosen to fix the housing supply in their baseline economy. We take a different approach: In our baseline estimates, we parameterize the housing production function to fit a price elasticity of housing starts of 6 , which is at the upper end of the empirical estimates. We then contrast our results with estimates that assume a constant housing stock, that is, a zero price elasticity of housing supply. This approach should provide bounds on the impact of policy changes.

We determine the values for $\psi_{1}$ and $\psi_{2}$ by assuming that the baseline parameterization is in a steady-state with constant housing stock. This implies that $H^{\text {new }}=\delta H^{S S}$. To 
Table 2: Calibrated Parameters and Target Moments

\begin{tabular}{clclcc}
\hline & & & \multicolumn{2}{c}{ Moment } \\
\cline { 3 - 5 } & Parameter & Value & Target & Data & Model \\
\hline$\omega$ & Weight on housing in utility & 0.09 & Housing share in consumption & $14.1 \%$ & $14.3 \%$ \\
$\lambda$ & Utility discount for rentals & 0.75 & Average homeownership rate & $68.8 \%$ & $68.9 \%$ \\
$\xi$ & Fixed cost of being landlord & 0.006 & Share of landlords in economy & $15.0 \%$ & $15.1 \%$ \\
$h^{\text {min }}$ & Minimum house size & 0.88 & Avg. size of owned / rented house & 2.2 & 2.1 \\
$H$ & Total housing supply & 0.876 & Housing stock / total labor income & 2.27 & 2.21 \\
\hline
\end{tabular}

Note: In our calibration we aim to match the data moment in column five by changing the parameter value in column three. The corresponding moment produced by the model is presented in column six.

determine the parameters, we solve the following system of simultaneous equations:

$$
\begin{gathered}
\epsilon=\frac{\partial H^{\text {new }}}{\partial p} \frac{p}{H^{\text {new }}}=\frac{1}{p \delta H^{S S}(1-\beta)}\left(\frac{1}{p \psi_{1} \psi_{2}}\right)^{\frac{1}{\left(\psi_{2}-1\right)}} \\
\delta H^{S S}=H^{\text {new }}=\psi_{1}\left(\frac{1}{p \psi_{1} \psi_{2}}\right)^{\frac{\psi_{2}}{\left(\psi_{2}-1\right)}}
\end{gathered}
$$

\subsection{Calibration Using Method of Moments Approach}

In this section we calibrate the remaining model parameters by matching important moments of the US economy. Table 2 summarizes the parameters and the moments we target. Housing Share in Consumption: To calibrate the weight of housing in the utility function, $\omega$, we target the share of housing in total household expenditure. Krueger and Jeske (2007) analyze NIPA data and report a value of $14.1 \%$ that has been nearly constant over the last 40 years. This corresponds to a value of $\omega$ of 0.09 in the model, which generates a housing share in consumption of $14.3 \%$.

Homeownership Rate: Another moment of the economy we would like to match is the aggregate homeownership rate. From the US Census Bureau's Statistical Abstract of the United States, Table 957, we find that the homeownership rate in 2005 was about $68.8 \%$. We match this aggregate homeownership rate by setting the value of the utility discount for rental units, $\lambda$ equal to 0.75 . As argued above, this rental discount is motivated both by the fact that owner-occupied housing stock is often of higher quality, and by the fact that owner-occupied housing can be adjusted to the preferences of the occupant. Figure 2 shows that this calibration does not only reproduce the average homeownership rate in this society well, but also generates a reasonable life-cycle profile of homeownership. Our model generates somewhat high home ownership rates in the early part of the life-cycle, and underpredicts ownership rates in the middle of the life-cyle. Overall, it approximates the development very well. 
Figure 2: Homeownership Rate for Different Age Groups

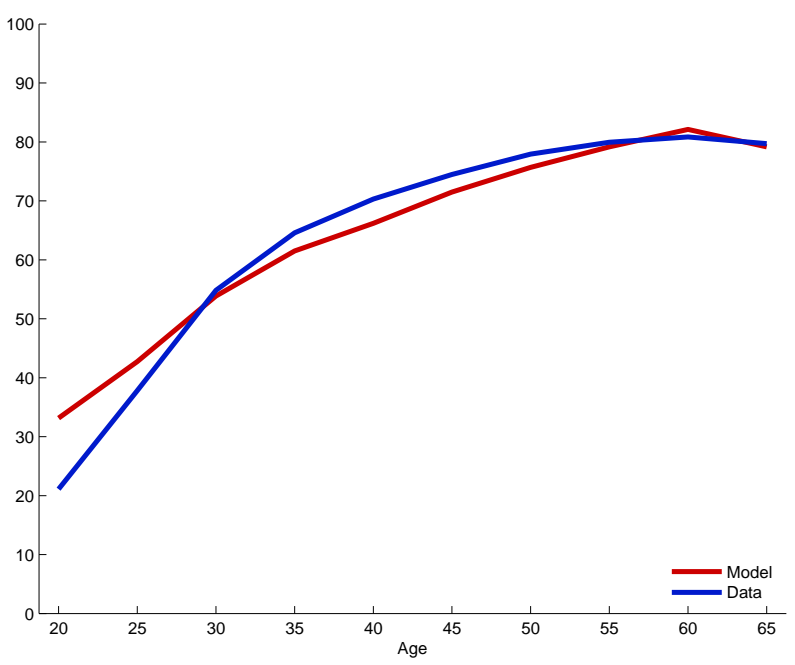

Note: In this figure age group 20, for example, refers to all 20-24 year olds. The red blue line shows average homeownership rates calculated from the Survey of Consumer Finances. The red line shows the corresponding moment in the baseline simulation.

Percentage of Landlords: We calibrate the fixed cost of becoming a landlord, $\xi$, to match the proportion of US households that are landlords. Chambers, Garriga and Schlagenhauf (2006) use the American Housing Survey to determine that about 15\% of American Households are landlords. A value of 0.006 for $\xi$ that corresponds to about $1.4 \%$ of mean income achieves a landlord rate of $15.1 \%$. In the US Census Bureau's 2004 Economic Survey, annual mean US households income was $\$ 60,528$, so $\xi$ represents an annual cost of being a landlord of approximately $\$ 739$.

Relative Size of Rental Housing: To calibrate the level of the smallest unit of housing available for purchase, we target the relative size of owner-occupied and rented houses. Using data from the 2003 American Housing Survey, we find that the average size of owneroccupied housing is about 1,960 square feet, while the average size of renter-occupied housing is 883 square feet. When we set $h_{\min }$ to 0.88 , our model produces a ratio of the average size of owner-occupied to rental housing of 2.1.

Value of Total Housing Stock: The total steady-state housing stock is determined by matching the ratio of the value of the total housing stock to total labor income in the economy. The value of the US housing stock is taken from Flow of Funds data, while total labor income is constructed as the sum of wage compensation and $70 \%$ of propriotor's income as reported in NIPA. We find that between 1995 and 2005, the average ratio of the 
value of housing stock to labor income was 2.27 . When setting $H$ equal to 0.876 , our model generates a ratio of 2.21 .

Other US Moments: This economy also reproduces a number of other U.S. moments that we did not specifically target. In our baseline calibration, $21.7 \%$ of homeowners change residence in each of our 5 year periods. Cocco (2005) looks at PSID data and finds that on average there is a $24.4 \%$ moving probability for homeowners over a 5 year period, but argues that some of that will be driven by exogenous events like job-related moves. In our model renters change housing every period since we assume that adjusting rental housing consumption is costless. This is consistent with data reported by Iacoviello and Pavan (2009), who show that on average renters move about every 2 years.

Mortgages in our benchmark economy have an average loan-to-value ratio of $38.6 \%$. This is precisely the figure that Poterba and Sinai (2008) found for the US economy in their analysis of the 2004 Survey of Consumer Finances. Our model also manage to replicate the age-distribution of loan-to-value ratios reasonably well. Again comparing with the values reported by Poterba and Sinai (2008), we find an average loan-to-value ratio of $69.5 \%$ for households aged 25 - 35 years of age, where the data reports $68.9 \%$. The model generates somewhat lower loan-to-value ratios for middle-aged households, and somewhat higher ratios for retirees than can be found in the data.

\section{$5 \quad$ Steady State Analysis}

The analysis of stationary equilibria is convenient as prices are constant. In this case, one does not have to deal with price expectations in the solution of the household problem. This allowed us to drop prices in our formulation of the household problem in (9) and (10) which simplifies the solution of the dynamic household problem significantly. However, when thinking about policy, analyzing stationary equilibria alone is not enough. We will thus turn to transitions between equilibria in section 6 of this paper.

In our equilibrium concept, the government runs a balanced budget at every point in time. Consequently, an agent's tax bill and the lump sum government transfer is an important redistributive channel. A reform that lowers equilibrium tax revenues would imply a reduction in the lump sum transfer that agents receive from the government and would hurt low-income and low-wealth households particularly hard. Equivalently, a reform that increases tax revenues by abolishing deductions can benefit low-income households through higher government transfers. ${ }^{27}$

\footnotetext{
${ }^{27}$ One could also choose to clear the government budget by adjusting the income tax rate - here the adjustment will impact high productivity households more. A robustness check has shown that this does not change any of the main results of this paper.
} 
We conduct a welfare analysis to investigate the differential well-being of specific subgroups of the population in the two steady states. As our welfare criterion we use expected discounted utility, which is equivalent to the value function $V$ in (9) and (10). We compare each household's welfare in the baseline case, $V$, and in the new stationary equilibrium following the policy change, $\hat{V}$. To make the comparison economically meaningful, we transform the welfare changes into consumption equivalent units. In other words, we consider the percentage change in one-period contemporaneous consumption that would make a specific agent in the baseline steady state as well off as an agent with the same vector of state variables in the alternative steady state. ${ }^{28}$

To express this more formally, let $c^{*}$ and $\tilde{h}^{*}$ be the solution to either (9) or (10) in the baseline steady state. That is, for all $j$, we have $V^{j}=u\left(c^{*}, \tilde{h}^{*}\right)+\beta(1-\kappa) \mathbf{E}\left[V^{j+1}\right]$, where $\kappa=0$ for $j<J$. For a given combination of state variables, the consumption equivalent percentage change $x$ can be found by inverting the following equation:

$$
\hat{V}^{j}=u\left(c^{*}(1+x), \tilde{h^{*}}\right)+\beta(1-\kappa) \mathbf{E}\left[V^{j+1}\right]
$$

One way to interpret this consumption equivalent variation is the following. Consider two countries with an economy in steady-state, one with the baseline US policy regime and another with the experiment calibration. ${ }^{29}$ Assume the welfare of a certain type of household is higher in the post-reform steady state than in the status quo. In that case, the consumption equivalent represents the one-time percentage increase in consumption today that households in the status quo would need to be offered to reject a switch of positions with a similar household in the new, post-reform steady state. Equivalently, if the reform has a negative welfare impact, the consumption equivalent $(x<0)$ is the one-time percentage reduction in consumption that households would be happy to accept to not have to switch with a similar households in the new, lower-welfare steady state.

In the remainder of this section, we discuss long-run or stationary effects of two policy interventions. First, we analyze the introduction of taxes on imputed rents, the implicit rental income that homeowners receive from their property. Second, we consider the elimination of the tax deductibility of mortgage interest payments.

\footnotetext{
${ }^{28} \overline{\text { We do not allow agents to re-optimize their }}$ choice of housing services in these calculations. That is, we are calculating the change in consumption that would, everything else equal, make the agent indifferent between both cases.

${ }^{29}$ In the two steady-states, households that are ex-ante similar (that is, have the same age and productivity), will make different choices, and have different wealth and housing positions.
} 


\subsection{Experiment 1: Taxes on Imputed Rents}

In the baseline model, there is no tax on the implicit rents that a property generates for an owner-occupier. Introducing a tax on imputed rents would end the asymmetric treatment of owner-occupied and rental housing. This tax might seem unusual, but it exists in practice in a number of OECD countries as we discuss in section 3.1. In our first experiment, we solve for the stationary equilibrium in a model with taxes on imputed rents. That is, we use the exact same calibration as in the baseline case, but set the indicator $\Psi_{1}$ to zero. Table 3 summarizes the effects of this experiment on prices and quantities.

Table 3: Quantity and Price Effects in Stationary Equilibrium

\begin{tabular}{lc|cc}
\hline $\begin{array}{l}\text { Moment } \\
\text { of Interest }\end{array}$ & $\begin{array}{c}\text { Experiments } \\
\text { Baseline } \\
\text { Model }\end{array}$ & $\begin{array}{c}\text { Imputed } \\
\text { Rents }\end{array}$ & $\begin{array}{c}\text { No Interest } \\
\text { Deduction }\end{array}$ \\
\hline House Price (normalized) & 1.000 & 0.958 & 0.985 \\
Rental Price (normalized) & 1.000 & 0.948 & 1.085 \\
Price-Rent Ratio & 19.12 & 19.32 & 17.35 \\
Housing Stock (normalized) & 1.000 & 0.770 & 0.908 \\
Rental Market (normalized) & 1.000 & 1.820 & 1.277 \\
Transfers (normalized) & 1.000 & 1.119 & 1.095 \\
Homeownership Rate & $68.9 \%$ & $53.2 \%$ & $61 \%$ \\
Share of Landlords & $15.1 \%$ & $24.8 \%$ & $17.7 \%$ \\
Average LTV & $38.6 \%$ & $25.2 \%$ & $26.1 \%$ \\
\hline
\end{tabular}

Note: The table shows moments of interest in the stationary equilibrium of three calibrations: the baseline model, the experiment with imputed rents $\left(\Psi_{1}=0\right)$, and the experiment without mortgage interest deductibility $\left(\Psi_{2}=0\right)$.

Prices and Quantities: A tax on imputed rents reduces the incentives of being a homeowner. In equilibrium, the homeownership rate drops by about 15 percentage points from $68.9 \%$ to $53.2 \%$. Correspondingly, house prices fall by a sizable $4 \%$ as more households choose to rent rather than buy. ${ }^{30}$ Despite an $82 \%$ growth in the absolute size of the rental market, rents drop by almost $5 \% .{ }^{31}$ This is driven by the removal of the asymmetry in tax treatment between rental and owner-occupied housing. Homeowners are now more willing to rent out some of their housing stock, since they no longer give up the tax benefit of owner-occupying. The share of landlords in the economy consequently increases from $13.5 \%$ to $24.8 \%$ after the removal of the tax-wedge. These results suggest that in the baseline calibration, the tax wedge induced homeowners to overconsume housing service out of their owned housing stock. ${ }^{32}$ Interestingly, young agents now consume more housing - mostly

\footnotetext{
${ }^{30}$ The decline in prices comes despite a significant decline in the housing stock of $23 \%$. With a fixed (or less elastic) housing supply, prices would fall by a larger amount. Appendix C shows this in more detail.

${ }^{31}$ Rental housing as a share of the total housing stock increases from 11 to 26 percent.

${ }^{32}$ Adjustement costs prevented home-owners from adjusting their owned housing quantity every period.
} 
renting it - while older and richer cohorts own bigger houses, but put a larger fraction of their property on the rental market. As a result of the taxation of owner-occupied housing, government revenues increase by around $11 \%$.

Welfare Comparisons: We now consider which groups are better off and which groups are worse off in the new steady state compared to the status quo. As described in section 5 , we use expected discounted utility, measured in one-time consumption equivalent units as our welfare criterion. That is, we calculate the one-time change in consumption that an agent in the baseline model would need to receive to be indifferent between the status quo and the new equilibrium.

Table 4: Stationary Welfare Effects - Model with Tax on Imputed Rents

\begin{tabular}{lcccccccccc}
\hline Income & \multicolumn{1}{c}{ Age Groups } \\
Groups & $20-24$ & $25-29$ & $30-34$ & $35-39$ & $40-44$ & $45-49$ & $50-54$ & $55-59$ & $60-64$ & $65+$ \\
\hline 1st octant & 0.281 & 0.277 & 0.277 & 0.277 & 0.273 & 0.263 & 0.246 & 0.216 & 0.180 & 0.089 \\
2nd octant & 0.255 & 0.253 & 0.253 & 0.253 & 0.247 & 0.235 & 0.217 & 0.193 & 0.163 & - \\
3rd octant & 0.231 & 0.227 & 0.221 & 0.216 & 0.209 & 0.193 & 0.179 & 0.165 & 0.150 & - \\
4th octant & 0.208 & 0.199 & 0.184 & 0.180 & 0.167 & 0.153 & 0.143 & 0.135 & 0.135 & - \\
5th octant & 0.185 & 0.163 & 0.149 & 0.141 & 0.103 & 0.090 & 0.083 & 0.083 & 0.087 & - \\
6th octant & 0.144 & 0.116 & 0.115 & 0.075 & 0.061 & 0.052 & 0.053 & 0.054 & 0.055 & - \\
7th octant & 0.089 & 0.086 & 0.050 & 0.043 & 0.037 & 0.034 & 0.032 & 0.033 & 0.039 & - \\
8th octant & 0.054 & 0.039 & 0.032 & 0.021 & 0.018 & 0.017 & 0.017 & 0.017 & 0.020 & - \\
\hline Average & 0.181 & 0.170 & 0.160 & 0.151 & 0.139 & 0.130 & 0.121 & 0.112 & 0.104 & 0.089 \\
\hline
\end{tabular}

Note: The table shows welfare changes in consumption equivalence units for different combinations of age and income. For example, the first number in the top left corner suggests that $20-24$ year olds need to receive a one-time consumption increase of $28.1 \%$ to be as well off living in the status quo than a person in the same age/productivity bracket in the new steady state. In the last column, there is only one number as all retiress receive the same fixed benefit payment as income.

Overall, welfare in a steady-state equilibrium in which imputed rents are taxed is higher than in the baseline scenario in which imputed rents are exempt from taxation. The average agent in the status-quo economy would have to receive a one-time consumption boost of $12.6 \%$ to be as well off as the corresponding agent with equal age and productivity in the new steady-state. Table 4 summarizes this result for all age groups and eight different levels idiosyncratic labor productivity. It is striking that all agents prefer the alternative regime to the status quo, independent of their income or age. For the youngest age group of 20 to 24 year olds, the effects are the largest. On average, those agents would need to receive a one-time consumption boost of more than $28 \%$ in order to be as well off as the corresponding agent in the new steady state. This finding is not surprising. As shown above, the policy shift reduces house prices and rents and allows young and poor agents in the new steady state to either rent larger dwellings or become home owners themselves, at significantly lower costs than in the status quo. Moreover, higher tax revenues - as a 
result of the tax increase on owner-occupied housing - allow the government to increase the steady state transfer. Those transfers have large effects on poor households whose marginal utility of consumption is high.

For older agents, who are more likely to owner-occupy, the effects are somewhat smaller but even retirees would require a one-time increase of $8.9 \%$ of consumption in the status quo to be equally well off in both steady states. More surprising is the fact that even rich home-owners who derive considerable amounts of housing services through owner-occupied housing prefer the alternative policy regime in which imputed rents are taxed. By renting out some of their owned housing stock, particularly in the younger years of their life, these agents are now able to shift their housing consumption $\tilde{h}$ closer towards the optimal level.

The results discussed above refer to an agent with a specific set of state variables who compares two alternative regimes in their respective stationary equilibrium. ${ }^{33}$ However, an immediate shift towards a new steady state is rarely a policy option. In reality a change of policy towards the taxation of imputed rents would imply that the a number of agents would suddenly find themselves in the uncomfortable position of owning a suboptimally large house. The agents would face the option of either paying the tax on owner-occupied housing, downsizing at considerable financial cost or renting out. It needs to be determined the long run benefits of the reform would offset those short term losses within the lifetime of a specific agent. By comparing only stationary equilibria and thus abstracting from the explicit transition to the new steady state, this important aspect is lost. We thus calculate the transition path explicitly in section 6.3.

\subsection{Experiment 2: Mortgage Interest Rate Deduction}

The possibility to deduct mortgage interest payments from taxable income makes housing an attractive asset for a large class of investors, since the after-tax return on housing is boosted for mortgage-financed housing investments. Our second experiment analyzes the potential effects of repealing the mortgage interest rate deduction. That is, we will compare the baseline model to an alternative calibration where the indicator $\Psi_{2}$ is set to zero. The effects on prices and quantities are summarized in the third column of table 3.

Prices and Quantities: Without the tax deductibility of mortgage interest payments, the purchase of large, debt-financed properties becomes significantly less attractive. Not surprisingly, house prices fall by $1.34 \%$ as homeowners reduce the size of their dwellings. The homeownership rate declines by over 8 percentage points. At the same time, the rental price increases by more than $8 \%$ as more agents compete for rental units. Unlike in the previous experiment, the incentive of becoming a landlord is still low relative to owner-

${ }^{33}$ In the alternative world, the same agent makes different choices and - in this specific experiment - reduces
the size of his home and shifts resources from the consumption of housing services to nondurable consumption 
occupying, as the asymmetry from the the tax exemption of imputed rents is still present. Older and richer households, who need not rely on mortgage financing take advantage of the decline in the price-to-rent ratio and offer more units in the rental markets. This allows the rental market to expand by $27 \%$ in size, depsite the relatively small change in the percentage of landlords. The decline in the attractiveness of mortgage financing precipitates a fall in loan-to-value ratios.

Table 5: Stationary Welfare Effects - Model with No Mortgage Interest Deductibility

\begin{tabular}{lcccccccccc}
\hline $\begin{array}{l}\text { Income } \\
\text { Groups }\end{array}$ & $20-24$ & $25-29$ & $30-34$ & $35-39$ & $40-44$ & $45-49$ & $50-54$ & $55-59$ & $60-64$ & $65+$ \\
\hline 1st octant & 0.180 & 0.175 & 0.170 & 0.167 & 0.144 & 0.122 & 0.120 & 0.104 & 0.076 & 0.090 \\
2nd octant & 0.164 & 0.159 & 0.146 & 0.151 & 0.131 & 0.119 & 0.123 & 0.111 & 0.090 & - \\
3rd octant & 0.151 & 0.138 & 0.115 & 0.131 & 0.117 & 0.112 & 0.123 & 0.117 & 0.104 & - \\
4th octant & 0.140 & 0.111 & 0.083 & 0.114 & 0.108 & 0.112 & 0.127 & 0.124 & 0.120 & - \\
5th octant & 0.128 & 0.074 & 0.058 & 0.100 & 0.092 & 0.106 & 0.122 & 0.123 & 0.121 & - \\
6th octant & 0.103 & 0.032 & 0.043 & 0.084 & 0.107 & 0.120 & 0.135 & 0.131 & 0.119 & - \\
7th octant & 0.068 & 0.011 & 0.048 & 0.102 & 0.116 & 0.123 & 0.122 & 0.120 & 0.118 & - \\
8th octant & 0.089 & 0.047 & 0.105 & 0.128 & 0.124 & 0.115 & 0.108 & 0.102 & 0.100 & - \\
\hline Average & 0.128 & 0.093 & 0.096 & 0.122 & 0.118 & 0.116 & 0.123 & 0.117 & 0.106 & 0.0900 \\
\hline
\end{tabular}

Welfare Comparisons: Again, the policy reform makes every agent better off in the long run. As before, young agents and renters benefit most from the policy shift. They gain the most from the increase in lump-sum transfers allowed by the fact that government revenues increase by about $10 \%$. Now, however, welfare effects are much less steep in the income and age dimension. Given the numbers cited in footnote 4, it may be surprising that rich households, who hold large housing stock, benefit from the removal of mortgage interest deductibility. This is due to two factors. First, the richest households have very low loanto-value ratios which implies that a large share of their house is cash financed, and these households are thus less affected by the taxation. ${ }^{34}$ This implies that the mortgage interest deduction is of limited benefit to them. Consequently, the agents whose welfare in the new steady-state is least increased are those in the third quarter of the income distribution, who require significant amounts of mortgage financing to afford a home of the size that is optimal given their level of income. Second, richer agents who own large houses and now increase the amount of housing they rent out. The marked increase in rents benefits those agents.

\footnotetext{
${ }^{34}$ This feature of our model can also be found in the data, and is discussed in Poterba and Sinai (2008). They find that average loan-to-value ratios peak for the households with an annual income of $\$ 75,000-\$ 125,00$ at $47.4 \%$. Households with annual income of over $\$ 250,000$ have average loan-to-value ratios of $29.4 \%$.
} 


\section{Transitions}

Policy analysis that is conducted by comparing stationary equilibria is useful for two purposes. First, it can be used as a comparison between the status quo and the policy regime of another country. This allows to consider, for example, which country a specific subgroup of the population would prefer to live in. Second, it can be seen as an evaluation of very long-run effects. However, this approach is less suited to describe the potential welfare consequences for a specific group of people that would result from a change in policy. This, however, is exactly the type of comparison that policy makers need to make when considering the effects of a shift in policy. In this part of the paper, we go beyond the comparison of stationary equilibria. We will consider the explicit transition following an unexpected and permanent change of the policy regime. This approach is not part of the existing literature that analyzes the impact of government intervention in the housing market.

\subsection{A Transition Path Under Perfect Foresight}

The explicit transition path from one stationary equilibrium to another is much harder to compute than the stationary equilibria themselves. In steady state, prices are constant and can thus be dropped in the formulation of the recursive household problem in section 2.2. During the transition from one steady state to another, prices are no longer constant. Instead, households form expectation about future prices which - in addition to being a function of current prices and aggregate variables like the size of the existing housing stock

- could in principle depend on the full distribution of agents over the state space, $\Omega_{t}$, a large and intractable object. The household problem - using a working cohort as an example thus becomes:

$$
V^{j}\left(h_{-1}, s, y, p^{r}, p, p_{-1}, T r\right)=\max _{s \prime, h, \tilde{h}}\left\{u(c, \tilde{h})+\beta \mathbb{E} V^{j+1}\left(h, s^{\prime}, y^{\prime}, p^{r \prime}, p^{\prime}, p, T r^{\prime}\right)\right\}
$$

subject to:

$$
\begin{aligned}
& p^{r}(h-\tilde{h})+\left(1+r+m I_{\{s<0\}}\right) s+\left(1-\tau^{s s}\right) y+p(1-\delta) h_{-1}-\max \{0, T-D\}+T r \\
& p^{r \prime}=\Gamma_{1}\left(\Omega_{t}, \ldots\right), p^{\prime}=\Gamma_{2}\left(\Omega_{t}, \ldots\right), T r^{\prime}=\Gamma_{3}\left(\Omega_{t}, \ldots\right)
\end{aligned}
$$$$
(1),(2),(3),(4),(5),(7)
$$

where $\Gamma_{1}, \Gamma_{2}$ and $\Gamma_{3}$ refer to the laws of motion for prices and transfers that households assume. Note that there is no aggregate uncertainty in the model. Instead of solving this problem with an approximate aggregation approach as in Krusell and Smith (1998), we can thus explicitly solve for a transition path under perfect foresight.

To calculate this transition, we adapt a method that was pioneered by Auerbach and Kotlikoff (1987) and that is summarized well in Rios-Rull (1997). This method can be applied to an economy without aggregate uncertainty that is currently in steady state and 
that faces a completely unexpected change in its fundamentals. The economy is assumed to converge to its new steady state within a given number of periods. Agents have perfect foresight and know the sequence of prices during the transition path. We check market clearing for the prices agents expect during the transition, to ensure that this method yields a self-confirming equilibrium similar to the Krusell-Smith type approach. The remainder of this section describes the solution algorithm in more detail.

Solution Algorithm for Transitions: For a given set of parameters and policy variables, define the vector of market clearing equilibrium prices and government transfers as $q_{t}$. Here, this vector has three elements: $p_{t}, p_{t}^{r}$ and $T r_{t}$. Recall that $\Omega_{t}$ captures the distribution of agents over age, income, owned housing and savings.

First, we have to guess the approximate length of the transition phase, T. Choosing a higher number is computationally intensive, but ensures that transition can be achieved within the number of periods considered. If transition can be achieved in a smaller number of periods, the last transition periods will already look very similar to the new steady state. In our simulations we choose a conservative $T=30$, but find that the transition path is not affected significantly by for values of $T$ greater than 15 . Note that this implies that a full transition to a new steady state after a change in policy parameters would take about 75 years. Certainly this transition period is a more relevant time horizon for most policy purposes, than comparing the welfare of inherently similar groups now and 75 years from now. After solving for the stationary equilibria before and after the policy change that we are interested in, we know the starting points $q_{0}$ and $\Omega_{0}$ as well as the end points $q_{T}$ and $\Omega_{T}$. The algorithm can now be described as follows:

1. Guess a sequence of $\widetilde{q}_{t}$ for $t=1, \ldots, T-1$.

2. Solve backwards for the value functions given the guessed values $\widetilde{q}_{t}$. For example, for period $T-1$, we can easily calculate $V_{T-1}=\max u_{T-1}+\beta V_{T}$ given $\widetilde{q}_{T-1}$ as $V_{T}$ is known in the stationary equilibrium. Ignore distriubtions, since we are not yet interested in market clearing.

3. Now solve forward: For period 1 , find the market clearing $\bar{q}_{1}$, given $V_{2}$ calculated in step 2 and $\Omega_{0}$. Also calculate $\bar{\Omega}_{1}$. This gives the sequence of $\bar{q}_{t}$ for $t=1, \ldots, T-1$.

4. Compare $\widetilde{q}_{t}$ and $\bar{q}_{t}$. If not the same, replace $\widetilde{q}_{t}$ by a weighted average of $\widetilde{q}_{t}$ and $\bar{q}_{t}$ and return to step 2.

5. Compare $\bar{\Omega}_{T}$ with $\Omega_{T}$ and increase $T$ if the two distributions differ. 


\subsection{Revenue Neutrality of Reforms}

A change in the policy regime affects tax revenues and the resulting transfers to agents. To account for this tax channel in the evaluation of alternative policies, we imposed a balanced government budget in the equilibrium concept for stationary equilibria used in section 5 . In the transition analysis, the government budget constraint can be set up in a number of ways. We can either require that the government breaks even in every period along the transition path, or we can require that they reset the transfers $T$ in the first period following the policy change to ensure that the policy-change is revenue neutral in present value terms.

While the latter approach has the advantage of working with a once-and-for-all change both in the policies and the tax rates, there are significant disadvantages from using this approach to conduct welfare analysis. The reason is that welfare effects of a reform can be artificially shifted between generations. Consider a reform that results in lower tax burdens at first, but makes up for the resulting deficits over time. Here, the benefits for the current generation will be artificially high as current cohorts enjoy high transfers without paying the appropriate level of taxes. This distorts the welfare analysis. For this reason, we conduct our analysis mainly using the former approach in which the government budget will be forced to balance in every period even during the transition.

\subsection{Experiment 1: Taxes on Imputed Rents}

The steady state effects of introducing a tax on imputed rents derived through owneroccupied housing have been discussed in detail in section 5.1. There we showed that the policy change results in a significant welfare gain for all agents. This was true even for the richest cohorts, which we expected to be hit hardest by the new tax and whose wellbeing would be least affected by an increase in the government transfer. It turns out that some of these agents, which would have benefited from a direct move to the new steady state, actually lose out on the transition towards such a steady state, when the policy gets introduced unexpectedly into the baseline steady state.

Figure 3 illustrates the development of prices and quantities during the perfect foresight transition. Following the reform, households with large houses attempt to downsize and sell parts of their housing stock. As the new tax reduces the incentive to owner-occupy, house prices plummet and fall by about $13 \%$ in the first period after the introduction of the tax on owner-occupied housing. The housing stock declines, but does not immediately adjust to the new steady state. As the housing stock approaches its new steady state over time, house prices recover and reach their new equilibrium level - which is less than $5 \%$ below the initial price level - after approximately 15 periods or 75 years. The figure further highlights that rents show a similar overshooting while the housing stock and the government transfer 
Figure 3: Transition Dynamics - Model with Tax on Imputed Rents
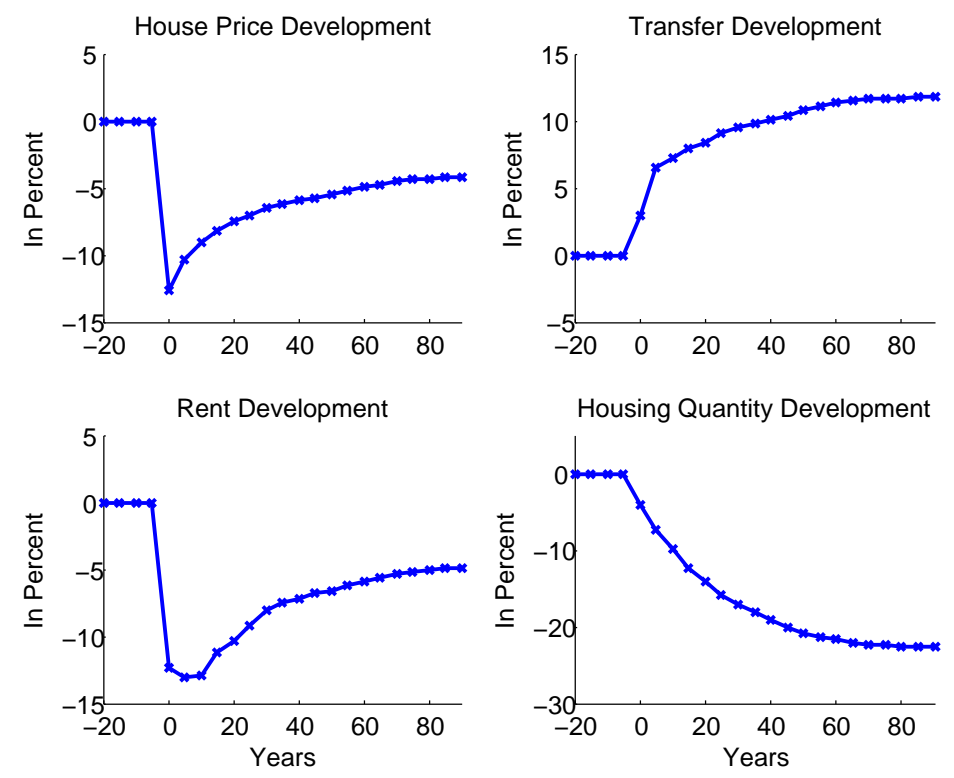

show a smoother adjustment to their new steady state values.

We now turn to the central question considered in this article: who wins and who loses from the policy reform? To answer this question, we conduct a welfare analysis similar to the one described in section 5. Here we are interested in the immediate change in expected discounted life-time utility following the reform. We want to measure this change in consumption equivalent units. Again, to formalize this description, let $\hat{V}^{j}$ represent the development of value function for an agent of age $j$ over the transition path. ${ }^{35}$ As before, let $c^{*}$ and $\tilde{h}^{*}$ be the solution to (9) or (10) in the baseline steady state. The consumption equivalent $x$ can then be determined as the solution to the following equation:

$$
u\left(c^{*}, \tilde{h}^{*}\right)+\beta(1-\kappa) \mathbf{E}\left[V^{j+1}\right]=u\left(c^{*}(1+x), \tilde{h}^{*}\right)+\beta(1-\kappa) \mathbf{E}\left[\hat{V}^{j+1}\right]
$$

Under this formulation, the consumption equivalent again has an intuitive interpretation. Consider two economies that are in the baseline steady state in period $t$. The first economy will unexpectedly introduce taxes on imputed rents in period $t+1$, while the second economy will not. The consumption equivalent variation determines the one-time change to period $t$ consumption of agents in the first economy required to ensure they are as well off as agents

\footnotetext{
${ }^{35} \overline{\text { This value function has dimensions }\left(s, h_{-1}, y\right)}$
} 
with the same immutable characteristics in the second economy. Again, it is important to note here that the consumption transfer is administered after the agents have optimized their behavior (without suspecting either a change in policy, or the potential for a consumption transfer). That is, we do not allow the agents to re-optimize their behavior in period $t$.

Table 6: Immediate Welfare Effects - Model with Tax on Imputed Rents

\begin{tabular}{lcccccccccc}
\hline $\begin{array}{l}\text { Income } \\
\text { Groups }\end{array}$ & $20-24$ & $25-29$ & $30-34$ & $35-39$ & $40-44$ & $45-49$ & $50-54$ & $55-59$ & $60-64$ & $65+$ \\
\hline 1st octant & 0.104 & 0.110 & 0.112 & 0.106 & 0.092 & 0.076 & 0.060 & 0.038 & 0.011 & -0.006 \\
2nd octant & 0.103 & 0.108 & 0.101 & 0.094 & 0.080 & 0.065 & 0.052 & 0.035 & 0.001 & - \\
3rd octant & 0.098 & 0.096 & 0.079 & 0.076 & 0.064 & 0.048 & 0.037 & 0.025 & -0.011 & - \\
4th octant & 0.092 & 0.078 & 0.056 & 0.057 & 0.045 & 0.028 & 0.020 & 0.012 & -0.023 & - \\
5th octant & 0.086 & 0.055 & 0.033 & 0.037 & 0.013 & -0.001 & -0.006 & -0.010 & -0.036 & - \\
6th octant & 0.078 & 0.031 & 0.011 & 0.012 & -0.003 & -0.014 & -0.018 & -0.021 & -0.037 & - \\
7th octant & 0.070 & 0.006 & -0.007 & -0.003 & -0.018 & -0.025 & -0.027 & -0.030 & -0.045 & - \\
8th octant & 0.058 & -0.013 & -0.017 & -0.013 & -0.033 & -0.033 & -0.031 & -0.035 & -0.053 & - \\
\hline Average & 0.086 & 0.059 & 0.046 & 0.046 & 0.030 & 0.018 & 0.011 & 0.002 & -0.024 & -0.006 \\
\hline
\end{tabular}

Table 6 shows the consumption changes required to make compansate agents for the introduction of the policy change. Along the transition path older and richer households lose as a result of the introduction of the new tax. We find that the richest households strongly prefer the status quo and that they would require a one-time consumption increase of over $5 \%$ to compensate them for the introduction of the tax on owner-occupied housing. Owners of large houses find themselves holding suboptimally large housing stock, following the introduction of the tax on imputed rents. The amount of owner-occupied housing they planned to consume under the old policy regime now comes with an additional tax burden and these households will thus be looking to sell or rent out part of their housing stock. This generates as supply overhang in the housing and rental market, leading a large fall in prices and rents. In a sense, those rich households are selling at fire-sale prices with significant effects on their wealth and life time utility.

Renters from the initial steady-state, on the other hand continue to gain from the reform. The house price overshoot allows those agents to significantly increase their housing consumption - both as owners and renters of larger homes in period $t+1$. They furthermore benefit from the increase in the lump-sum transfer payments in period $t+1$ (see Figure 3 ). When one analyzes the welfare change by housing stock owned, it becomes apparent that renters are the only group who would favor the introduction of tax on owner-occupied housing. Even poor households, who only own (and owner-occupy) a small amount of housing are worse off, despite them also receiving increased lump-sum transfers.

Given these results we believe that a restriction of welfare analyses to steady states is 
Figure 4: Transition Dynamics - Model with No Mortgage Interest Deductibility
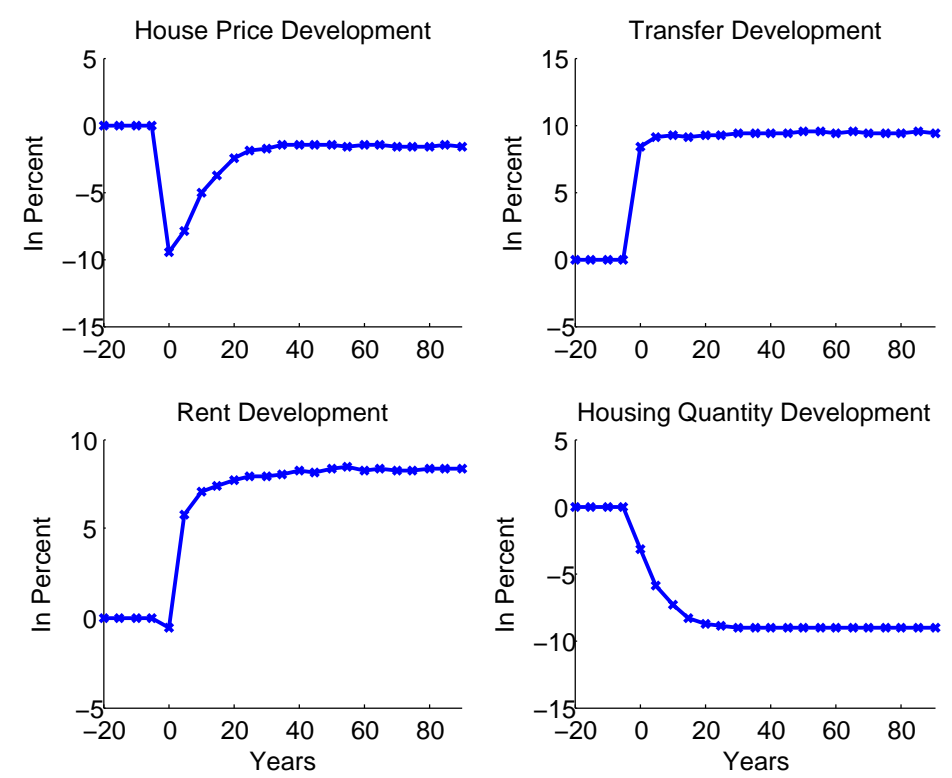

insufficient from a policy perspective. Rather, it is important to analyze how each group of agents currently present would be affected by a shift to the new policy. While the long-run effects of such policy changes may well be positive, many currently present housholds (and voters) could suffer in the transition to the new steady state.

\subsection{Experiment 2: Mortgage Interest Rate Deduction}

Unlike the previous experiment, where homeowners are worse off on the transition path, the removal of mortgage tax deductibility leaves all agents better off, even during the transition. Not surprisingly, though, the welfare gains are smaller when compared to the immediate transition to steady-state considered in section 5.2.

As before, agents at the extremes of the wealth distribution fare much better than those in the middle, which are rich enough to own, but require substantial external financing. Agents with high loan-to-value ratios still gain from the policy reform (due to higher transfers and a higher rental income), but their gains are modest and on the order of 2 to 4 percent. Young renters, on the other hand, gain the welfare equivalent of an 11 percent increase of consumption as a result of the reform. Again, this result is primarily driven by the increase in tax revenues that can be redistributed across the economy. Rich households 
Table 7: Immediate Welfare Effects - Model with No Mortgage Interest Deductibility

\begin{tabular}{lcccccccccc}
\hline $\begin{array}{l}\text { Income } \\
\text { Groups }\end{array}$ & $20-24$ & $25-29$ & $30-34$ & $35-39$ & $40-44$ & $45-49$ & $50-54$ & $55-59$ & $60-64$ & $65+$ \\
\hline 1st octant & 0.110 & 0.115 & 0.115 & 0.108 & 0.088 & 0.067 & 0.055 & 0.034 & 0.018 & 0.032 \\
2nd octant & 0.110 & 0.117 & 0.107 & 0.102 & 0.083 & 0.070 & 0.069 & 0.051 & 0.019 & - \\
3rd octant & 0.108 & 0.109 & 0.088 & 0.094 & 0.083 & 0.077 & 0.083 & 0.070 & 0.022 & - \\
4th octant & 0.107 & 0.094 & 0.068 & 0.089 & 0.087 & 0.087 & 0.098 & 0.087 & 0.028 & - \\
5th octant & 0.106 & 0.073 & 0.050 & 0.087 & 0.074 & 0.083 & 0.098 & 0.092 & 0.038 & - \\
6th octant & 0.105 & 0.049 & 0.040 & 0.078 & 0.088 & 0.093 & 0.106 & 0.099 & 0.050 & - \\
7th octant & 0.112 & 0.027 & 0.035 & 0.091 & 0.095 & 0.100 & 0.101 & 0.098 & 0.060 & - \\
8th octant & 0.139 & 0.026 & 0.088 & 0.132 & 0.116 & 0.109 & 0.104 & 0.096 & 0.075 & - \\
\hline Average & 0.112 & 0.076 & 0.074 & 0.098 & 0.089 & 0.086 & 0.089 & 0.078 & 0.039 & 0.032 \\
\hline
\end{tabular}

who own large houses that they finance to a large degree by equity, are less affected by the loss of their mortgage interest deductibility. At the same time, the significant increase in rents benefits those agents a lot as they act as landlords.

\section{Conclusion}

This paper considers the effects of government intervention in the housing market in a heterogeneous agent, overlapping-generations general equilibrium model. We explicitly model the supply of rental units by households, which allows us to capture the effect of changes in rents on all households' budget constraints. When comparing the stationary distributions of the baseline model and alternative policy regimes, we confirm the results reported in the existing literature: households across all age and income categories would benefit from the removal of the mortgage interest deductibility and the taxation of owner-occupied rents.

However, we argue that from a policy perspective, analyzing the transition between those steady states is at least as important as the comparison of steady states themselves. Here we find that the introduction of taxes on owner-occupied rents will harm all agents in the initial steady state, except for renters who benefit from increased lump-sum transfers. However, the removal of the mortgage interest deductibility will benefit most households, even along the transition path. This suggests that the removal of mortgage interests is a significantly more attractive policy option in the US than the taxation of owner-occupied rents.

Our model can be used as a sandbox for a wide range of additional experiments. For example, our model can be used to investigate the aggregate and distributional effects of temporary policy interventions like the first-time homebuyers' tax credits authorized by Congress as part of the American Recovery and Reinvestment Act of 2009. This is possible 
in the context of our model as we explicitly calculate transition paths.

Another interesting calculation-that we leave for a future version of the paper-considers the effect of policy alternatives on immigrants versus non-immigrants. Borjas (2002) finds that immigrants are substantially less likely to own even after controlling for a wide range of observables. If this finding does indeed reflect a cultural difference, it could potentially be expressed in the preference specifications of subgroups. In that case, the model is well suited to ask the question how immigrants are affected by government intervention in the housing market. 


\section{References}

Adda, J. and Cooper, R. (2003): Dynamic Economics - Quantitative methods and Applications. MIT Press Cambridge.

Antonji, J.G. and Villanueva, E. (2003): The Marginal Propensity to Spend on Adult Children, NBER Working Paper 9811.

Attanasio, O. and Browning, M.(1995): Consumption Over the Life Cycle and Over the Business Cycle. American Economic Review, 85(5).

Auerbach, A and Kotlikoff, L.J. (1987): Dynamic Fiscal Policy. Cambridge University Press. New York.

Berkovec, J. and Fullertion, D. (1992): A General Equilibrium Model of Housing, Taxes and Portfolio Choice. Journal of Political Economy, 100(2).

Blackley, D.M. (1999): The Long-Run Elasticity of New Housing Supply in the United States: Empirical Evidence for 1950 to 1994. Journal of Real Estate Finance and Economics, $18(1)$

Borjas, G.J. (2002): Homeownership in the Immigrant Population. Journal of Urban Economics.

Case, K.E. and Shiller, R.J. (1990): Forecasting Prices and Excess Returns in the Housing Market. Real Estate Economics, 18(3),

Caplin, A., Chan, S., Freeman, C. and Tracy, J. (1999): Household Asset Portfolios and the Reform of the Housing Finance Market. TIAA-CREF Research Dialog 59.

Chambers, M., Garriga, C. and Schlagenhauf, D.E. (2006): The Tax Treatment of Homeowners and Landlords and the Progressivity of Income Taxation. Forthcoming in Journal of Monetary Economics.

Chambers, M., Garriga, C. and Schlagenhauf, D.E. (2009): Accounting for Changes in the Homeownership Rate. International Economic Review, 50(3).

Chen, K. (2009): A Life-Cycle Analysis of Social Security with Housing. Review of Economic Dynamics, forthcoming.

Cocco, J.F. (2005): Portfolio Choice in the Presence of Housing. Review of Financial Studies, 18(2).

Davis, M.A. and Heathcote, J. (2005): The Price and Quantity of Residential Land in the United States. Journal of Monetary Economics, 54(8).

DeNardi, M. (2004): Wealth Inequality and Intergenerational Links. Review of Economic Studies, 71(3).

Diaz, A. and Luengo-Prado, M.J. (2008): On the User Cost and Homeownership, Review of Economic Dynamics, 11(3).

Fernandez-Villaverde, J. and Krueger, D. (2002): Consumption and Saving over the Life

Cycle: How important are consumer durables? Proceedings of the 2002 North American 
Summer Meetings of the Econometric Society.

Fullerton, D. (1984): Which Effective Tax Rate? NBER Working Paper 1123.

Galster, G.C. (1987): Homeowners and Neighborhood Reinvestment. Duke University Press, Durham, NC.

Gervais, M. (2002): Housing Taxation and Capital Accumulation. Journal of Monetary Economics, 49.

Glaeser, E.L. and Shapiro, J.M. (2003): The Benefits of the Home Mortgage Interest Deduction. Tax Policy and the Economy 17.

Glaeser E.L., Gyourko J and Saks R.E. (2005): Why Have Housing Prices Gone Up?," American Economic Review, American Economic Association, vol. 95(2).

Goetzmann, W.N. (1993): Accounting for Taste: Art and the Financial Markets Over Three Centuries. The American Economic Review, 83(5).

Goetzmann, W.N. and Spiegel, M. (2002): The Policy Implications of Portfolio Choice in Underserved Mortgage MarketsIn Nicholas P. Retsinas and Eric S. Belsky, eds. Low Income Homeownership: Examining the Unexamined Goal. Brookings Institution Press.

Gruber, J.W. and R.F. Martin (2003): Does Housing Wealth Make us Less Equal: The Role of Durable Goods in the Distribution of Wealth. Working Paper.

Hall, R.E. (1988): Intertemporal Substitution in Consumption. Journal of Political Economy, 96(2).

Harding, J.P., Rosenthal, S.S. and Sirmans, C.F. (2007): Depreciation of Housing Maintenance and House Price Inflation: Estimates from a Repeat Sales Model. Journal of Urban Economics, 61(2).

Hendershott, P.H. and Hu, S.C. (1981): Inflation and Extraordinary Returns on OwnerOccupied Housing: Some Implications for Capital Allocation and Productivity Growth. Journal of Macroeconomics, 3(2).

Iacoviello, M. (2005): House Prices, Borrowing Constraints and Monetary Policy in the Business Cycle. American Economic Review, 95(3).

Iacoviello, M. and Neri, S. (2009): Housing Market Spillovers: Evidence from an Estimated DSGE Model. AEJ Macro, forthcoming.

Iacoviello, M. and Pavan, M. (2009): Housing and Debt over the Life Cycle and Over the Business Cycle. Working Paper.

Kahn, J.A. (2008): What drives House Prices? Mimeo.

Kiyotaki, N., Michaelides, A. and Nikolov, K. (2008): Winners and Losers in the Housing Market. Working Paper.

Krueger, D. and Jeske, K. (2007): Housing and the Macroeconomy: The Role of Implicit Guarantees for Government Sponsored Enterprises. Working Paper.

Krusell, P. and Smith, T. (1998): Income and Wealth Heterogeneity in the Macroeconomy. Journal of Political Economy, 106(5). 
Landvoigt, T. (2010): Housing Demand During the Boom. The role of Expectations and Downpayment Constraints. Working Paper

Leigh, W.A. (1980): Economic Depreciation of the Residential Housing Stock of the United States, 1950-1970. The Review of Economics and Statistics, 62(2).

Lustig, H. and Van Nieuwerburgh, S. (2005): Housing Collateral, Consumption Insurance and Risk Premia: An Empirial Perspective. The Journal of Finance, 60(3)

Mayer, C.J. and Somerville, C. T. (2000): Residential Construction: Using the Urban Growth Model to Estimate Housing Supply. Journal of Urban Economic 48

Nakajima, M. (2005): Rising Earnings Instability, Portfolio Choice, and Housing Prices. Mimeo.

Ogaki, M. and Reinhart, C.M. (1998): Measuring Intertemporal Substitution: The Role of Durable Goods. Journal of Political Economy, 106(5).

Ortalo-Magne, F. and Rady, S. (2006): Housing Market Dyanmics: On the Contribution of Income Shocks and Credit Constraints. Review of Economic Studies 73.

Piazzesi, M., Schneider, M. and Tuzel, S. (2007): Housing, Consumption and Asset Prices, Journal of Financial Economics, 83(3).

Pistaferri, L. (2003): Anticipated and Unanticipated Wage Changes, Wage Risk, and Intertemporal Labor Supply. Journal of Labor Economics, 21(3).

Poterba, J. and Sinai, T. (2008): Tax Expenditures for Owner-Occupied Housing: Deductions for Property Taxes and Mortgage Interest and the Exclusion of Imputed Rental Income. The American Economic Review, 98(2)

Queisser, M. and Whitehouse, E. (2005): Pensions at a Glance: Public Policies Across OECD Countries. MPRA Paper 16349.

Rios-Rull, J. (1997): Computation of equilibria in heterogeneous agent models. Federal Reserve Bank of Minneapolis Staff Report 231

Rosen, H. and Rosen, K. (1980): Federal Taxes and Homeownership: Evidence from Time Series. Journal of Political Economy, 88(1).

Rosen, H.S. (1979): Housing Decision and the US Income Tax: An Economteric Analysis. Journal of Public Economics, 11.

Silos, P. (2007): Housing, Portfolio Choice and the Macroeconomy. Journal of Economic Dynamics and Control, 31(8)

Smith, L.B., Rosen K.T. and Fallis, G. (1988): Recent Developments in Economic Models of Housing Markets. Journal of Economic Literature, 26(1).

Tauchen G. and Hussey, R. (1991): Quadrature-Based Methods for Obtaining Approximate Solutions to Nonlinear Asset Pricing Models. Econometrica, 59(2).

Yang, F. (2008): Consumption over the Life Cycle: How Different is Housing? Working Paper.

Yao, R. and Zhang, H. (2005): Optimal Consumption and Portfolio Choices with Risky Housing and Borrowing Constraints. Review of Financial Studies, 18(1). 


\section{A Analytical Appendix}

\section{A.1 Consumption-Renting Decision for given House Size}

Solving our model is computationally intensive. However, a significant simplification of the numerical problem can be achieved by first solving for two control variables in a static problem. For a given combination of state variables, savings and tenure choice, the allocation of resources towards the consumption of the numeraire good and the consumption of housing services can be pinned down with a simple first order condition.

First, consider the problem of an agent who decides not to buy a house, but instead to rent. For a given set of state variables and given the savings choice, the problem how to allocate resources to either consumption or housing services is static. When we denote the resources available for consumption and renting by $X$, the problem becomes

$$
\begin{array}{r}
\max _{\tilde{h}}\{u(c, \tilde{h})\} \\
\text { s.t.: } c+p^{r} \tilde{h} \leq X
\end{array}
$$

Not surprisingly, the optimal allocation of resources, equates the marginal utility that can be derived from the two uses of funds, $p^{r} u_{C}=u_{H}$. Given the functional form we have assumed, this allows us to derive the demand for housing services (and thus the rental demand) for this particular agent as

$$
\tilde{h}_{\text {renter }}^{*}=\left(\frac{\omega \lambda}{p^{r}}\right)^{\frac{1}{1-\alpha}} \frac{c}{\lambda}=X\left(p^{r}+\lambda\left(\frac{\omega \lambda}{p^{r}}\right)^{\frac{1}{\alpha-1}}\right)^{-1}
$$

Second, consider the case of an agents who choses to buy a house of size $h$. For a given set of states and controls, we can again determine the resources available for consumption and housing services. For convenience, we first calculate those resources for the hypothetical case where the agent decides to rent out his home completely. Again, denote those resources by $X$. This implies that the agent rents out the complete house and then uses the market to acquire the housing services she desires. Here, the problem is exactly analogous to the renter problem and the interior solution is then also given by (24).

However, an agent with significant financial wealth who owns a small house might run into constraint (1). In that case, the homeowner is trying to rent additional housing units which we do not allow by assumption. Hence, the owners choice of housing services can be 
expressed as

$$
\tilde{h}_{\text {owner }}^{*}=\min \left\{h, X\left(p^{r}+\lambda\left(\frac{\omega \lambda}{p^{r}}\right)^{\frac{1}{\alpha-1}}\right)^{-1}\right\} \text {. }
$$

\section{A.2 Policy Alternatives in the Budget Constraint}

For notational convenience, we will start with the case of no deductions. This is equivalent to setting $\Psi_{1}=\Psi_{2}=0$ in equation (17). That is, mortgage interest payments cannot be deducted from the tax bill and the tax on rental income is levied both on real rental income as well as imputed rental income from owner-occupied housing. It is important to note that this is not the equivalent to current US policy which is given by $\Psi_{1}=\Psi_{2}=1$. For both potential deductions considered in this paper, we illustrate below the effect on the household's budget constraint both in the homeowner and renter case. We ensure that overall tax payments of each individual do not result in a net subsidy.

To simplify notation, we define the amount of resources to be spent on c and $\tilde{h}$ as $X$. This is analogous to section A.1. The intra-temporal problem is then again given by the maximization of period utility $u(c, \tilde{h})$ given the constraint $c+p^{r} \tilde{h} \leq X$.

Homeowner Case: In the absence of any deductions, the owner's budget constraint can be written as follows, where $T$ denotes the owner's tax burden:

$$
c+s^{\prime}+p h=p^{r}(h-\tilde{h})+(1+r) s+\left(1-\tau^{s s}\right) y+p(1-\delta) h_{-1}+T r-T
$$

For the homeowner, the amount of resources available for consumption and housing services is thus given by

$$
X=T r+\left(1-\tau^{s s}\right) y+p^{r} h+p\left((1-\delta) h_{-1}-h\right)-A C+(1+r) s-s^{\prime}-T
$$

In terms of the model's solution, the only effect of the policy alternatives is to alter equation (22). The constraint becomes

$$
\begin{aligned}
& c+p^{r} \tilde{h}-\Psi_{1} \cdot p^{r} \tilde{h} \tau^{r} \leq X-\Psi_{2} \cdot r I_{\{s<0\}} s \\
& c+p^{r} \tilde{h}\left(1-\Psi_{1} \cdot \tau^{r}\right) \leq X-\Psi_{2} \cdot r I_{\{s<0\}} s .
\end{aligned}
$$

By defining the amount of effective resources as $\hat{X}$ and the effective price of housing services for the owner as $\hat{p}$, we can use the exact same program to solve the intra-temporal problem 
for any combination of policy alternatives.

$$
\begin{aligned}
\hat{X} & \equiv X-\Psi_{2} \cdot r I_{\{s<0\}} s \\
\hat{p} & \equiv p^{r}\left(1-\Psi_{1} \cdot \tau^{r}\right) \\
c+\hat{p} \tilde{h} & \leq \hat{X}
\end{aligned}
$$

Renter Case: The renter case can be derived analogously. For the renter, the amount of available resources is given by

$$
X^{r}=T r+\left(1-\tau^{s s}\right) y+p\left((1-\delta) h_{-1}\right)-A C+(1+r) s-s^{\prime}-T
$$

Note that the mortgage interest rate deduction can apply to a renter, as the renter can potentially be a former homeowner who just sold her home and is paying off the mortgage in the current period. Following the same steps as above and noting that deduction 1 does not apply, we find that

$$
\begin{aligned}
\hat{X}^{r} & \equiv X^{r}-\Psi_{2} \cdot I_{\{s<0\}} r s \\
\hat{p}^{r} & \equiv p^{r}\left(1-\Psi_{1} \cdot \tau^{r}\right) \\
c+\hat{p}^{r} \tilde{h} & \leq \hat{X}
\end{aligned}
$$

\section{A.3 Voluntary Savings}

In the numerical solution, we follow Yao and Zhang (2005) who define voluntary savings instead of actual savings. In equation (7), the lower bound on savings, which is equivalent to the maximum mortgage the household can get, depends on the value of the house and is thus varying not constant. Instead, we can define voluntary savings as

$$
b^{\prime}=s^{\prime}-(1-d) h p
$$

so that whenever $b^{\prime}$ is set equal to zero, the household holds the maximum mortgage allowed, $(1-d) h p$. This formulation has the advantage of creating a rectangular constraint set with $c, b^{\prime}$ and $h$ bounded below by zero. This comes at the cost of having to carry the previous period's price as an additional state. A further downside of this formulation is that it implies that mortgages involve margin calls and that negative home-equity is not allowed.

Using this alternative formulation of savings, we can express key equations in our model in terms of $b$. The derivation of equations for the numerical implementation as in section A.2 is straightforward. For example, the homeowner's resources $X$ and the tax bill $T$ can 
be expressed as.

$$
\begin{aligned}
& X=T r+y+p^{r} h+h_{-1}\left((1-\delta) p-(1-d)(1+r) p_{-1}\right)-p(d h+A C)+(1+r) b-b^{\prime}-T \\
& T=\sum\left(\begin{array}{l}
\tau^{y} y \\
\tau^{s} r\left(b-(1-d) p_{-1} h_{-1}\right) I_{\left\{b>(1-d) p_{-1} h_{-1}\right\}} \\
\tau^{r} p^{r} h
\end{array}\right)
\end{aligned}
$$




\section{B Computational Appendix}

State Space and Choice Variables: Before describing our solution algorithm in more detail, it will be useful to define the state space and control variables. A household current state depends on four variables: the housing stock $h_{-1}$ and savings $s$ at the beginning of the period, the current realization of the persistent, idiosyncratic income shock $\eta$ and the household's age $j$. A household chooses whether to rent or buy and in the latter case how many housing units to purchase $h$. Other choice variables are savings $s$ and the amount of housing services consumed in the current period $\tilde{h}$.

The housing variable can take a value of zero if the household decides to rent, and a value in the set $\left\{h^{\min }, h^{\min }(1-\delta)^{-1}, h^{\min }(1-\delta)^{-2}, \ldots\right\}$ if the household decides to be a homeowner. Restricting the housing choice to the delta-spaced housing grid is a convenient assumption in the presence of fixed transaction costs. In section A.3 we introduced the concept of voluntary savings $b=s-(1-d) h_{-1} p_{-1}$. This reformulation of the model allows us to work with a rectangular constraint set as the lower bound on choices of $b$ is always zero and thus independent of the housing choice. We approximate the state variable $b$ with a fine grid. Using the parameters of the estimated autoregressive income process described in section 4.1, we use a procedure introduced by Tauchen and Hussey (1991) as described in Adda and Cooper (2003) to discretize the income process with an eight-state Markov process. As outlined in the calibration section 4, the model contains nine working cohorts and a group of retirees. Dying agents are replaced with an equal measure of newborn agents and we normalize the total measure of households to one. The relative size of the cohorts can thus be derived from the retirees' survival probability.

Calculation of Stationary Equilibria: Stationary equilibria are calculated for a given policy regime and constant prices and rents. At first, we start with a given level of lump sum transfers. Given those transfers and prices, we can calculate optimal policies by solving an infinite horizon problem for retirees - using value function iteration - and by using the resulting value function to solve the working cohorts' problem backwards. Using the optimal policy correspondence, we simulate the economy forward until the stationary distribution of agents over the state space is achieved. We can then check market clearing in the housing and rental market. The equilibrium prices are found using the nonlinear optimization routine fminsearchcon in Matlab. In a last step, we adjust the level of transfers and iterate until the government budget constraint clears as well.

To simplify the problem, we first calculate the amount of resources available for consumption of the nondurable good and housing services for all combinations of states and remaining controls. That allows us to solve a simple static optimization problem as outlined in section A.1. Here, it is important to carefully consider corner solutions. Using the opti- 
mal allocation of resources to those two uses, we calculate the momentary utility flow for all possible choices and store those in a large multidimensional object. The actual iteration on the value function is then simple and fast. To further improve computational speed, we vectorize the problem such that there is only a single maximization per iteration.

In the simulation, we do not track a large number of households, but instead store the exact distribution on the state space grid. This allows for a fast simulation routine given the Markov properties of both the exogenous processes and the policy correspondences. The calculation of the transition path is explained in detail in section 6 . 


\section{Robustness Check: Fixed Housing Supply}

As outlined in section 4.1, calibrating the housing supply elasticity is difficult. In the main part of this paper we work with a price elasticity of housing starts of 6 , a relatively high number. As a robustness check, we use this section to report results for an alternative specification that uses an elasticity of zero - a fixed housing supply. By showing that the results do not change in economically significant ways, we provide evidence for the generality of our results.

Of course, with a price elasticity of housing supply of of zero, price effects are more pronounced as quantities do not adjust. For example, in the first experiment both the house price and rental price fall much more in the fixed housing supply version, whereas the expansion of the rental market is significantly smaller than before. The quantitiy effects with fixed $\mathrm{H}$ are summarized in table 8 .

Table 8: Quantity and Price Effects in Stationary Equilibrium (Fixed H)

\begin{tabular}{lc|cc}
\hline \multirow{2}{*}{$\begin{array}{l}\text { Moment } \\
\text { of Interest }\end{array}$} & $\begin{array}{c}\mid c \\
\text { Experiments } \\
\text { Model }\end{array}$ & $\begin{array}{c}\text { Imputed } \\
\text { Rents }\end{array}$ & $\begin{array}{c}\text { No Interest } \\
\text { Deduction }\end{array}$ \\
\hline House Price (normalized) & 1.000 & 0.839 & 0.812 \\
Rental Price (normalized) & 1.000 & 0.843 & 0.99 \\
Price-Rent Ratio & 19.12 & 19.04 & 15.54 \\
Housing Stock (normalized) & 1.000 & 1.000 & 1.000 \\
Rental Market (normalized) & 1.000 & 1.182 & 1.221 \\
Transfers (normalized) & 1.000 & 1.077 & 1.014 \\
Homeownership Rate & $68.9 \%$ & $70.6 \%$ & $71.4 \%$ \\
Share of Landlords & $13.5 \%$ & $16.9 \%$ & $14.4 \%$ \\
\hline
\end{tabular}

Note: The table shows moments of interest in the stationary equilibrium of three calibrations: the baseline model, the experiment with imputed rents $\left(\Psi_{1}=0\right)$, and the experiment without mortgage interest deductibility $\left(\Psi_{2}=0\right)$.

However, our main findings regarding welfare still go through. The qualitative result that welfare consequences derived by comparing stationary equilibria can be overturned when explicitly considering the transition path still holds true. Tables 9 to 12 summarize the welfare effects for both experiments. Figures 5 and 6 contain the corresponding quantity movements over the transition period. 
Table 9: Stationary Welfare Effects - Tax on Imputed Rents (Fixed H)

\begin{tabular}{lcccccccccc}
\hline Income & \multicolumn{1}{c}{ Age Groups } \\
Groups & $20-24$ & $25-29$ & $30-34$ & $35-39$ & $40-44$ & $45-49$ & $50-54$ & $55-59$ & $60-64$ & $65+$ \\
\hline 1st octant & 0.225 & 0.226 & 0.232 & 0.239 & 0.242 & 0.240 & 0.229 & 0.206 & 0.179 & 0.1036 \\
2nd octant & 0.214 & 0.220 & 0.235 & 0.247 & 0.247 & 0.243 & 0.229 & 0.203 & 0.170 & - \\
3rd octant & 0.202 & 0.213 & 0.236 & 0.242 & 0.239 & 0.231 & 0.215 & 0.193 & 0.169 & - \\
4th octant & 0.192 & 0.209 & 0.233 & 0.234 & 0.224 & 0.212 & 0.195 & 0.180 & 0.165 & - \\
5th octant & 0.182 & 0.203 & 0.227 & 0.218 & 0.176 & 0.159 & 0.142 & 0.138 & 0.134 & - \\
6th octant & 0.163 & 0.196 & 0.213 & 0.157 & 0.125 & 0.107 & 0.105 & 0.097 & 0.092 & - \\
7th octant & 0.147 & 0.183 & 0.120 & 0.107 & 0.090 & 0.083 & 0.078 & 0.077 & 0.078 & - \\
8th octant & 0.130 & 0.106 & 0.093 & 0.080 & 0.068 & 0.061 & 0.057 & 0.056 & 0.056 & - \\
\hline Average & 0.182 & 0.194 & 0.199 & 0.190 & 0.176 & 0.167 & 0.156 & 0.144 & 0.130 & 0.103 \\
\hline
\end{tabular}

Table 10: Stationary Welfare Effects - No Mortgage Interest Deduction (Fixed H)

\begin{tabular}{lcccccccccc}
\hline Income & \multicolumn{1}{c}{ Age Groups } \\
Groups & $20-24$ & $25-29$ & $30-34$ & $35-39$ & $40-44$ & $45-49$ & $50-54$ & $55-59$ & $60-64$ & $65+$ \\
\hline 1st octant & 0.207 & 0.205 & 0.203 & 0.204 & 0.185 & 0.168 & 0.167 & 0.151 & 0.127 & 0.135 \\
2nd octant & 0.197 & 0.199 & 0.196 & 0.205 & 0.189 & 0.185 & 0.193 & 0.176 & 0.145 & \\
3rd octant & 0.188 & 0.188 & 0.184 & 0.203 & 0.196 & 0.201 & 0.213 & 0.202 & 0.170 & \\
4th octant & 0.181 & 0.174 & 0.170 & 0.204 & 0.206 & 0.221 & 0.235 & 0.229 & 0.219 & \\
5th octant & 0.175 & 0.154 & 0.160 & 0.221 & 0.203 & 0.218 & 0.226 & 0.221 & 0.206 & \\
6th octant & 0.155 & 0.126 & 0.166 & 0.194 & 0.207 & 0.211 & 0.224 & 0.210 & 0.190 & \\
7th octant & 0.126 & 0.125 & 0.142 & 0.197 & 0.201 & 0.201 & 0.193 & 0.189 & 0.180 & \\
8th octant & 0.191 & 0.138 & 0.198 & 0.217 & 0.199 & 0.181 & 0.170 & 0.159 & 0.152 & \\
\hline Average & 0.178 & 0.164 & 0.178 & 0.206 & 0.198 & 0.198 & 0.203 & 0.192 & 0.174 & 0.135 \\
\hline
\end{tabular}

Table 11: Immediate Welfare Effects - Tax on Imputed Rents (Fixed H)

\begin{tabular}{lcccccccccc}
\hline Income & \multicolumn{1}{c}{ Age Groups } \\
Groups & $20-24$ & $25-29$ & $30-34$ & $35-39$ & $40-44$ & $45-49$ & $50-54$ & $55-59$ & $60-64$ & $65+$ \\
\hline 1st octant & 0.112 & 0.119 & 0.121 & 0.112 & 0.093 & 0.072 & 0.052 & 0.026 & -0.001 & -0.011 \\
2nd octant & 0.115 & 0.121 & 0.111 & 0.100 & 0.081 & 0.063 & 0.046 & 0.023 & -0.013 & - \\
3rd octant & 0.113 & 0.111 & 0.089 & 0.084 & 0.067 & 0.048 & 0.034 & 0.015 & -0.027 & - \\
4th octant & 0.111 & 0.093 & 0.066 & 0.067 & 0.050 & 0.029 & 0.017 & 0.003 & -0.040 & - \\
5th octant & 0.109 & 0.069 & 0.042 & 0.048 & 0.015 & -0.001 & -0.008 & -0.017 & -0.052 & - \\
6th octant & 0.105 & 0.042 & 0.020 & 0.019 & 0.000 & -0.014 & -0.021 & -0.027 & -0.051 & - \\
7th octant & 0.099 & 0.015 & -0.000 & 0.004 & -0.016 & -0.027 & -0.030 & -0.036 & -0.058 & - \\
8th octant & 0.091 & -0.007 & -0.007 & -0.004 & -0.033 & -0.034 & -0.033 & -0.040 & -0.065 & - \\
\hline Avergae & 0.107 & 0.070 & 0.055 & 0.054 & 0.032 & 0.016 & 0.007 & -0.006 & -0.038 & -0.011 \\
\hline
\end{tabular}


Table 12: Immediate Welfare Effects - No Mortgage Interest Deduction (Fixed H)

\begin{tabular}{lcccccccccc}
\hline Income & \multicolumn{1}{c}{ Age Groups } \\
Groups & $20-24$ & $25-29$ & $30-34$ & $35-39$ & $40-44$ & $45-49$ & $50-54$ & $55-59$ & $60-64$ & $65+$ \\
\hline 1st octant & 0.123 & 0.131 & 0.131 & 0.118 & 0.090 & 0.063 & 0.044 & 0.019 & 0.004 & 0.023 \\
2nd octant & 0.129 & 0.139 & 0.128 & 0.115 & 0.091 & 0.074 & 0.064 & 0.039 & 0.001 & - \\
3rd octant & 0.132 & 0.134 & 0.110 & 0.111 & 0.098 & 0.088 & 0.086 & 0.063 & 0.003 & - \\
4th octant & 0.135 & 0.121 & 0.089 & 0.110 & 0.108 & 0.102 & 0.103 & 0.083 & 0.007 & - \\
5th octant & 0.140 & 0.098 & 0.069 & 0.110 & 0.087 & 0.092 & 0.100 & 0.085 & 0.017 & - \\
6th octant & 0.145 & 0.072 & 0.057 & 0.096 & 0.102 & 0.099 & 0.106 & 0.092 & 0.032 & - \\
7th octant & 0.160 & 0.047 & 0.047 & 0.109 & 0.105 & 0.103 & 0.099 & 0.090 & 0.042 & - \\
8th octant & 0.202 & 0.042 & 0.107 & 0.155 & 0.123 & 0.112 & 0.104 & 0.090 & 0.058 & - \\
\hline Average & 0.146 & 0.098 & 0.092 & 0.116 & 0.101 & 0.092 & 0.088 & 0.070 & 0.021 & 0.023 \\
\hline
\end{tabular}

Figure 5: Transition Dynamics - Tax on Imputed Rents (Fixed H)
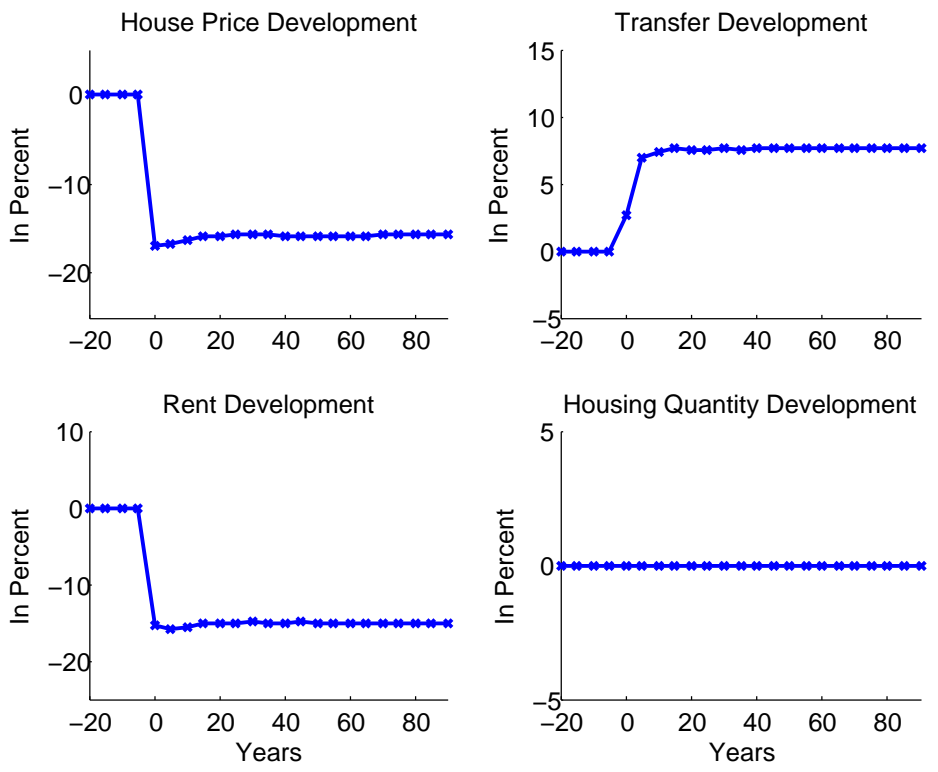
Figure 6: Transition Dynamics - No Mortgage Interest Deduction (Fixed H)
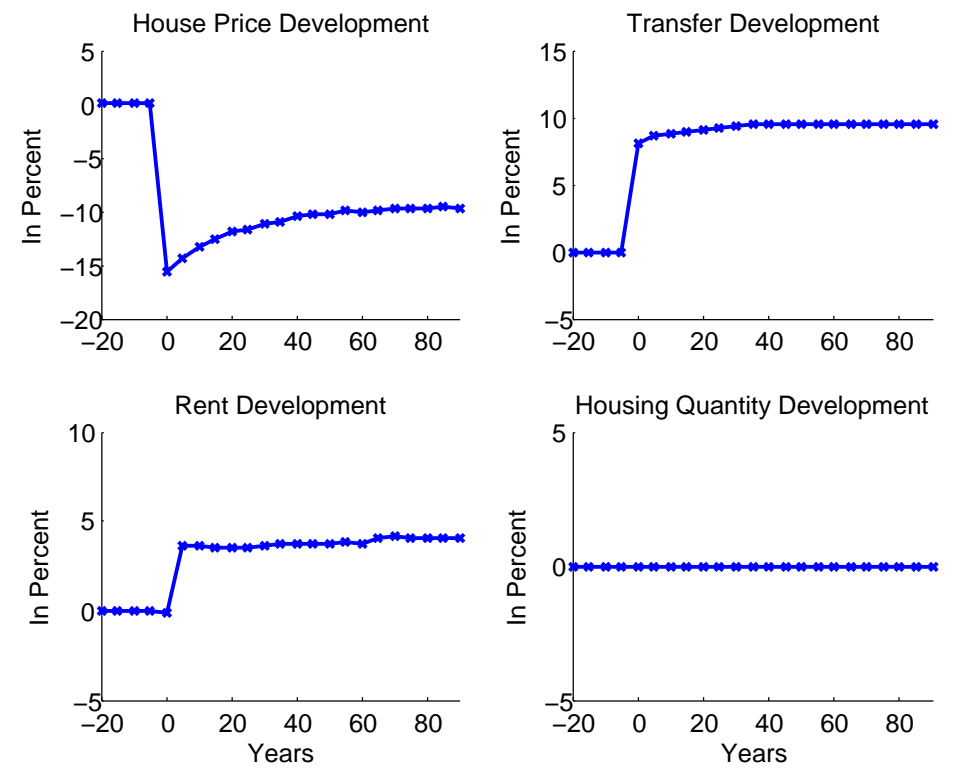